\title{
Autonomous profiling float observations of the high-biomass plume downstream of the Kerguelen Plateau in the Southern Ocean
}

\author{
M. Grenier ${ }^{1,4, *}$, A. Della Penna ${ }^{2,5}$, and T. W. Trull ${ }^{3,6}$ \\ ${ }^{1}$ Antarctic Climate and Ecosystems Cooperative Research Centre, Hobart, Tasmania, Australia \\ ${ }^{2}$ Quantitative Marine Sciences PhD Program, Institute for Marine and Antarctic Studies, University of Tasmania, and \\ Commonwealth Scientific and Industrial Research Organisation, Hobart, Tasmania, Australia \\ ${ }^{3}$ Commonwealth Scientific and Industrial Research Organisation, Oceans and Atmosphere Flagship, \\ Hobart, Tasmania, Australia \\ ${ }^{4}$ Laboratoire d'Etudes en Géophysique et Océanographie Spatiales (CNRS/CNES/IRD/University of Toulouse), \\ Toulouse, France \\ ${ }^{5}$ Sorbonne Universités, Univ Paris Diderot Cité, UMR 7159, LOCEAN-IPSL, 75005, Paris, France \\ ${ }^{6}$ Antarctic Climate and Ecosystems Cooperative Research Centre, Hobart, Tasmania, Australia \\ *now at: Earth, Ocean and Atmospheric Sciences, University of British Columbia, Vancouver, Canada
}

Correspondence to: M. Grenier (melaniegrenier14@yahoo.fr)

Received: 7 November 2014 - Published in Biogeosciences Discuss.: 15 December 2014

Revised: 18 March 2015 - Accepted: 3 April 2015 - Published: 11 May 2015

\begin{abstract}
Natural iron fertilisation from Southern Ocean islands results in high primary production and phytoplankton biomass accumulations readily visible in satellite ocean colour observations. These images reveal great spatial complexity with highly varying concentrations of chlorophyll, presumably reflecting both variations in iron supply and conditions favouring phytoplankton accumulation. To examine the second aspect, in particular the influences of variations in temperature and mixed layer depth, we deployed four autonomous profiling floats in the Antarctic Circumpolar Current near the Kerguelen Plateau in the Indian sector of the Southern Ocean. Each "bio-profiler" measured more than 250 profiles of temperature $(T)$, salinity $(S)$, dissolved oxygen, chlorophyll $a(\mathrm{Chl} a$ ) fluorescence, and particulate backscattering $\left(b_{\mathrm{bp}}\right)$ in the top $300 \mathrm{~m}$ of the water column, sampling up to 5 profiles per day along meandering trajectories extending up to $1000 \mathrm{~km}$. Comparison of surface Chl $a$ estimates (analogous to values from satellite images) with total water column inventories revealed largely linear relationships, suggesting that these images provide credible information on total and not just surface biomass spatial distributions. However, they also showed that physical mixed layer depths are often not a reliable guide to biomass distributions. Regions of very high Chl $a$ accumulation (1.5-
\end{abstract}

$10 \mu \mathrm{g} \mathrm{L}^{-1}$ ) were associated predominantly with a narrow $T$ $S$ class of surface waters. In contrast, waters with only moderate Chl $a$ enrichments $\left(0.5-1.5 \mu \mathrm{g} \mathrm{L}^{-1}\right)$ displayed no clear correlation with specific water properties, including no dependence on mixed layer depth or the intensity of stratification. Geostrophic trajectory analysis suggests that both these observations can be explained if the main determinant of biomass in a given water parcel is the time since leaving the Kerguelen Plateau. One float became trapped in a cyclonic eddy, allowing temporal evaluation of the water column in early autumn. During this period, decreasing surface Chl $a$ inventories corresponded with decreases in oxygen inventories on sub-mixed-layer density surfaces, consistent with significant export of organic matter $(\sim 35 \%)$ and its respiration and storage as dissolved inorganic carbon in the ocean interior. These results are encouraging for the expanded use of autonomous observing platforms to study biogeochemical, carbon cycle, and ecological problems, although the complex blend of Lagrangian and Eulerian sampling achieved by the floats suggests that arrays rather than single floats will often be required, and that frequent profiling offers important benefits in terms of resolving the role of mesoscale structures on biomass accumulation. 


\section{Introduction}

The productivity of the Southern Ocean is important for many reasons. It supports fisheries and high-conservationvalue marine mammal and bird populations (Constable et al., 2003; Nicol et al., 2000), influences the carbon dioxide content of the atmosphere (Sarmiento and Le Quéré, 1996; Sigman and Boyle, 2000; Watson et al., 2000), and affects the magnitude of nutrient supply to large portions of the global surface ocean (Sarmiento et al., 2004). This productivity is limited by the scarce availability of iron $(\mathrm{Fe})$ as an essential micronutrient (Boyd and Ellwood, 2010; Boyd et al., 2007; Martin, 1990). Island sources of Fe elevate productivity and produce downstream "plumes" of elevated phytoplankton biomass that contrasts with the general HNLC (high-nutrient, low-chlorophyll) nature of the Southern Ocean (Blain et al., 2007; de Baar et al., 1995; Mongin et al., 2009; Pollard et al., 2009; Nielsdóttir et al., 2012). Ship-based studies of several of these regions, focused on the influence of $\mathrm{Fe}$ on carbon (C) transfer to the ocean interior (Blain et al., 2008; Salter et al., 2007), have revealed a diversity of responses in terms of intensity of enhanced productivity, biomass accumulation, and ecosystem structures. This diversity derives from interactions between the supply and bioavailability of iron with other drivers of productivity such as temperature, water column stratification and stability, light levels, and the possibility of co-limitation by other nutrients (Assmy et al., 2013; Boyd et al., 1999, 2001; Queguiner, 2013).

Assessing influences on productivity, biomass accumulation, carbon export, and carbon dioxide $\left(\mathrm{CO}_{2}\right)$ uptake in the Southern Ocean is challenging because of variations across many scales, including weather, seasonal, and interannual timescales, and sub-mesoscale, mesoscale, and circumpolar frontal space scales (Joubert et al., 2014; Le Quéré et al., 2010; Lenton et al., 2013; Levy, 2003; Nicol et al., 2000; Shadwick et al., 2015; Sokolov and Rintoul, 2007; Swart et al., 2014; Thomalla et al., 2011; Weeding and Trull, 2014). Satellite observations offer extensive space-time coverage (Martinez et al., 2009; Moore and Abbott, 2000) but may provide a biased view if surface distributions are not representative of water column inventories. Important ways that bias could arise include lack of direct correlations of surface values with their vertical extents (e.g. high surface chlorophyll values might be predominantly associated with shallow accumulations, through the promotion of production by higher light levels in shallow mixed layers; Sverdrup, 1953), the presence of unobserved subsurface chlorophyll maxima (Carranza et al., 2015; Schlitzer, 2002), or the variation of phytoplankton to chlorophyll ratios with growth conditions (Cloern et al., 1995; Fennel and Boss, 2003; Goericke and Montoya, 1998).

These difficulties of observation become even more acute for carbon export estimates, which require either flux measurements (e.g. from moored or free-drifting sediment traps or radionuclide activities; Planchon et al., 2014; Savoye et al., 2008) or the partitioning of changes in state variables across biogeochemical vs. oceanographic causes (e.g. nitrate depletions in surface waters or oxygen consumption at mesopelagic depth; Matear et al., 2000; Trull et al., 2015). Obtaining estimates of carbon export and the depth of its penetration into the ocean interior are important to determining impacts on the climate system, because variations in these two factors have similar influence to variations in total primary production in terms of the sequestration of $\mathrm{CO}_{2}$ from the atmosphere (Boyd and Trull, 2007). Notably, export estimates expressed as " $e$-ratio" fractions of primary production (Maiti et al., 2013), or as " $f$-ratio" fractions of production derived from "new" nitrate supply (Savoye et al., 2004), vary widely in the Southern Ocean, with the possibility that these efficiencies are increased by natural iron fertilisation (Jouandet et al., 2011; Trull et al., 2008).

This space-time complexity is abundantly demonstrated by the "mosaic of blooms" (i.e. patchiness pattern) encountered in waters downstream from the Kerguelen Plateau during the KEOPS2 field programme in austral spring (OctoberNovember 2011), as detailed in many papers in a special issue of Biogeosciences (d'Ovidio et al., 2015; Trull et al., 2015; Lasbleiz et al., 2014; Laurenceau-Cornec et al., 2015; Cavagna et al., 2014). Much of the mesoscale spatial variation in biomass accumulation, as seen in satellite images and animations (Mongin et al., 2009; d'Ovidio et al., 2015; Trull et al., 2015), appears to result from the interleaving of iron-enriched water parcels that have transited the Kerguelen Plateau with surrounding iron-poor waters, as demonstrated by analysis of satellite-altimetry-based circulation estimates and surface drifter trajectories (Park et al., 2014a; d'Ovidio et al., 2015). However, shipboard studies close to the plateau (Mosseri et al., 2008; d'Ovidio et al., 2015; Blain et al., 2015; Trull et al., 2015; Lasbleiz et al., 2014; Laurenceau-Cornec et al., 2015) suggest that other factors are also likely to play a role, including mixed layer depth and upper water column stratification.

To explore the influence of variations in these water column properties on bloom structure at larger scale, in particular further from the plateau than could be surveyed by ship, we deployed autonomous profiling drifters. The first one was successfully launched during the KEOPS2 field programme in late October 2011, and the other three during the MyctO-3D-MAP (referred to as MYCTO, from now on in this text) interdisciplinary survey between late January and early February 2014. Given the extent of the Kerguelen biomass plume (> $1000 \mathrm{~km}$; Mongin et al., 2009), the remoteness from ports, and the generally rough sea states, the use of autonomous platforms is arguably the only affordable way to survey this region. As shown in Fig. 1, these deployments returned data from a large proportion of the enriched biomass plume downstream of the Kerguelen Plateau.

In this paper, we use the bio-profiler observations to address three questions: 

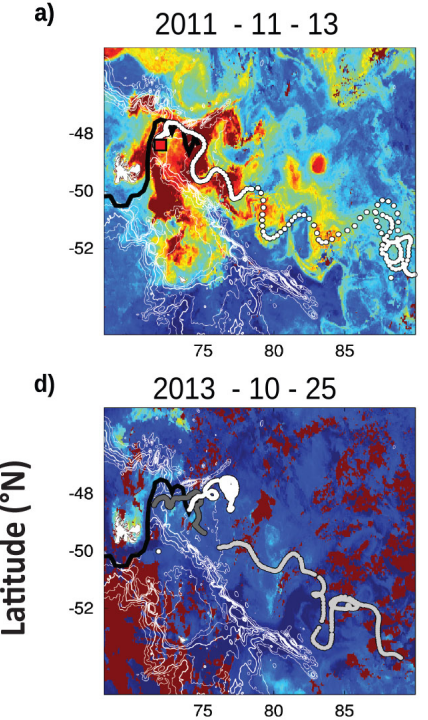

g)

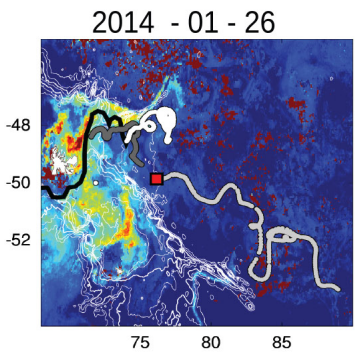

b)

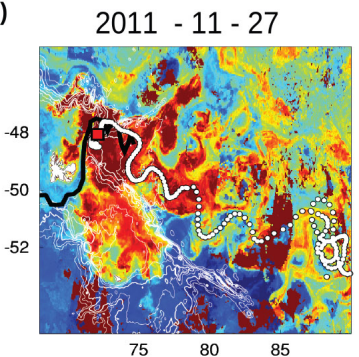

e)

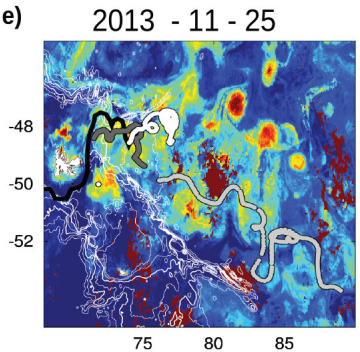

h)

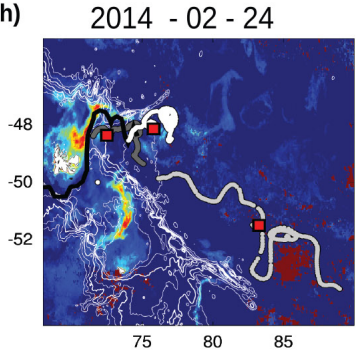

c)

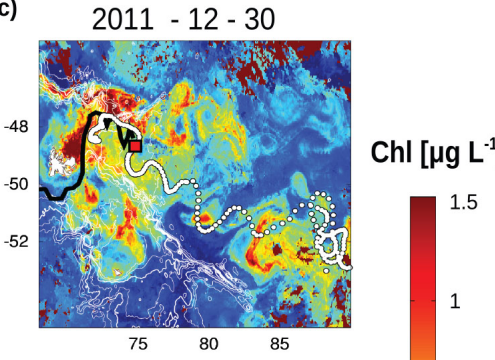

f)

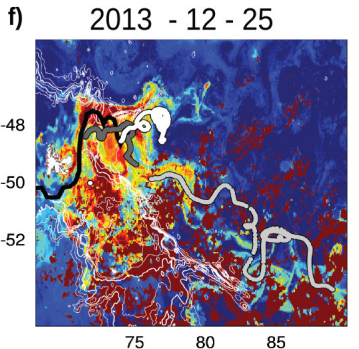

i)

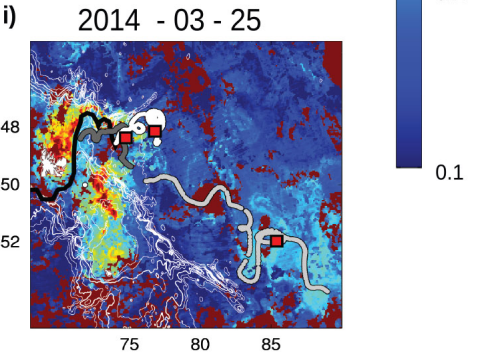

Longitude $\left({ }^{\circ} \mathrm{E}\right)$

Figure 1. Maps of bio-profiler trajectories (white and grey lines) over remotely sensed chlorophyll $a$ distributions (a-h): daily, $4 \mathrm{~km}$ CLS/CNES product; (i): weekly composite from GlobColour $4 \mathrm{~km}$ product. Top row: 2011 bloom season for bio-profiler \#1. Middle and bottom rows: 2013/2014 bloom and beginning of post-bloom season for bio-profilers \#2 (light-grey trajectory), \#3 (dark-grey trajectory), and \#4 (white trajectory). Red squares indicate the bio-profiler locations corresponding to the day of the image. The thick black line refers to the position of the Polar Front measured from hydrographic samples by Park et al. (2014a).

1. Do satellite images of surface chlorophyll provide an unbiased guide to the spatial distribution of total water column chlorophyll, or are they biased by lack of knowledge of variations in the vertical extent of chlorophyll distributions or the presence of subsurface chlorophyll maxima?

2. Do regions of high biomass correlate with particular oceanographic properties, such as warmer or fresher waters, or the intensity of stratification? If so, are these properties determined locally or by the upstream origins of the different water parcels?

3. Can the fate of surface enrichments in biomass be determined (and eventually quantified) from along-trajectory temporal variations in biogeochemical properties, for example by progressive downward movement of fluorescence or particulate backscattering signals or decreases in oxygen in subsurface waters?

\section{Methods}

\subsection{Float sensor and mission configurations}

The float deployment locations are provided in Table 1, along with their identification numbers which provide access to their full data sets via the Australian Integrated Marine Observing System (www.imos.org.au). Float deployment was done in 2011 by manual transfer to a small boat and then the sea, and in 2014 by deploying the floats from the ship deck inside cardboard boxes designed to readily disintegrate after release. The autonomous profiling floats were all of the same design (model APF9I, Teledyne Webb Inc.). Each was equipped with pumped, poisoned, thermosalinographs (model SBE 41CP-2.0, Sea-Bird Inc.), end-cap-mounted unpumped oxygen optodes (model 3830, Aanderaa Inc.), and two-channel bio-optical sensors (model FLBBAP2, WET Labs Inc.) strapped onto the lower third of the float hull with their optical ports facing horizontally to minimise possible 
Table 1. Bio-profiler deployments.

\begin{tabular}{rrrrrrrr}
\hline$\#$ & Hull\# $^{\mathrm{a}}$ & WMO\# $^{\mathrm{b}}$ & UTC date & Lat. $\left({ }^{\circ} \mathrm{N}\right)$ & Long. $\left({ }^{\circ}\right.$ E) & Campaign & Last profile (UTC date) \\
\hline 1 & 5122 & 1901329 & 29 October 2011 & -48.5 & 72.2 & KEOPS2 & 22 April 2012 \\
2 & 6684 & 5904882 & 26 January 2014 & -49.9 & 76.2 & MYCTO & 14 April 2014 \\
3 & 6682 & 1901338 & 28 January 2014 & -48.4 & 71.5 & MYCTO & 14 April 2014 \\
4 & 6683 & 1901339 & 4 February 2014 & -48.6 & 74.0 & MYCTO & 14 April 2014 \\
\hline
\end{tabular}

${ }^{\mathrm{a}}$ Hull\#: serial number for the bio-profiler body. ${ }^{\mathrm{b}}$ WMO\#: World Meteorological Organization identification number for the bio-profiler data stream.

interferences from particle accumulation. Owing to the structure of the firmware for the floats and the varying power requirements for the sensors, the sampling rates differed for the physical and biogeochemical parameters. Temperature and salinity were sampled at the highest rates, yielding values at $2 \mathrm{dbar}$ intervals (used in this work as equivalent to $2 \mathrm{~m}$ depth intervals without density corrections), whereas oxygen, fluorescence, and backscatter were sampled at 10 dbar intervals, except for bio-profiler \#1, where they were sampled at $5 \mathrm{dbar}$ intervals in the first $150 \mathrm{~m}$.

Temperature and salinity calibrations were performed by Sea-Bird Inc., with estimated accuracy and precision of better than $0.005^{\circ} \mathrm{C}$ and 0.01 , respectively (Oka and Ando, 2004). These variables, used as water mass proxies and to estimate mixed layer depths and stratification intensity (expressed as the Brunt-Väisälä frequency), helped to determine whether dissolved oxygen evolutions were mainly due to physical processes or to biological production or respiration processes. The oxygen optodes were calibrated at CSIRO prior to mounting on the floats against a 20-point matrix of four temperatures (0.5-30) and five oxygen saturations (0-129\%) using the methods detailed in Weeding and Trull (2014). Similar sensors exhibited drift during a 6month mooring deployment in the Southern Ocean of less than $1.7 \mu \mathrm{mol} \mathrm{kg}^{-1}$ over the 6 months (Weeding and Trull, 2014).

The bio-optical sensors measured chlorophyll $a$ fluorescence via stimulation/emission at 470/695 nm and particulate backscattering at $700 \mathrm{~nm}$. Chlorophyll $a$ fluorescence is a useful proxy for chlorophyll $a$ concentration and standing stocks of phytoplankton biomass (Falkowski and Kiefer, 1985; Huot et al., 2007). Particulate backscattering provides a good proxy for particulate organic carbon (Stramski et al., 2008; Cetinić et al., 2012). The bio-optical fluorescence sensors were calibrated (by the manufacturer, WET Labs Inc.) against fluorescent uranine solutions as working standards, and cross-referenced to prior measurements of a laboratory culture ( $25 \mathrm{mg} \mathrm{m}^{-3}$ chlorophyll) of the diatom Thalassiosira weissflogii to yield chlorophyll estimates. These calibrations are warranted to yield linear responses with precisions among multiple sensors of better than $10 \%$, and (after one cycle of testing and replacement with the manufacturer) we obtained reproducibility for the set of three floats deployed in 2014 of better than $4 \%$ based on measurements with fluores- cent and non-reflective plastics (Earp et al., 2011). Accordingly, calculation of the chlorophyll fluorescence from the float data was done by removal of the background dark signals measured prior to deployment and scaling to chlorophyll using the manufacturer's calibrations. Similarly, the retrieval of particulate backscattering, $b_{\mathrm{bp}}\left(\mathrm{m}^{-1}\right)$, at $700 \mathrm{~nm}$ from the backscatter raw transmitted measurement (counts) was done by applying the manufacturer-provided scaling factor after correction for dark counts (i.e. measured signal output of the backscatterometer in clean water with black tape over the detector), with the additional steps of removal of the pure seawater backscattering contribution (Zhang et al., 2009) and scaling from the limited solid angle sensor measurement to the total backscattered hemisphere based on relations estimated from observations for a wide range of marine particles (Boss and Pegau, 2001; Sullivan et al., 2012).

In contrast to typical Argo programme float missions for climate studies (http://www.argo.ucsd.edu/), which consist of deep $(2000 \mathrm{~m})$ profiles every 10 days, the bio-profilers were programmed to focus on the upper water column and carried out continuous profiling between the surface and $300 \mathrm{~m}$ depth, achieving 4 to 6 profiles per day, depending on the stratification. This temporal resolution was intended to allow for examination of daily cycles related to insolation, photosynthesis, and respiration. In practice, it proved difficult to extract clear cycles because of aliasing from spatial variations. Consequently, after several weeks for the 2011 KEOPS2 deployment of bio-profiler \#1, the frequency of profiles was reduced to twice daily to provide extended battery life while still obtaining night and day observations to allow for insolation quenching of the fluorescence response to be evaluated and corrected, and thus to avoid inappropriate inference of subsurface chlorophyll maxima from the fluorescence signal (Sackmann et al., 2008; Xing et al., 2012). For bio-profilers \#2, \#3, and \#4 deployed in 2014, the missions were further refined, via automated telemetric switching of mission configuration files, to carry out a deep profile to $\sim 1500 \mathrm{~m}$ every 3 days to provide deep reference points for temperature, salinity, and oxygen observations, and also with the intention of slowing the development of bio-fouling of the bio-optical sensors by exposing surface organisms to high pressures. 


\subsection{Float data quality control}

Extensive experience from the Argo programme with profiling float measurements for temperature $(T)$ and salinity $(S)$, including recovery of floats for post deployment tests (Oka and Ando, 1994), suggests that these sensors reliably deliver accurate and precise observations (to better than $0.005^{\circ} \mathrm{C}$ and 0.01 salinity) over multi-annual deployments. Given our much shorter bio-profiler deployments (3 to 6 months) and their observed $T-S$ relationships which fall within those of the ship-based KEOPS2 observations (Fig. 2c), we assume these variables are correct and make no further assessment or correction. We similarly accept the oxygen observations, given our careful attention to their pre-deployment calibration, their reasonable range of surface water oxygen supersaturations $(96-103 \%$ for low-chlorophyll waters and extending up to $108 \%$ in correlation with very high chlorophyll waters, as discussed further below), and their deep ocean values (950-1000 m depths) which fall within the range of nearby ship observations and show no temporal trends and standard deviations of less than $4 \mu \mathrm{mol} \mathrm{kg}{ }^{-1}$ over the deployment periods (ranging from 1 to $3.9 \mu \mathrm{mol} \mathrm{kg}^{-1}$ for the four bio-profilers).

To evaluate the possibility of temporal sensor drifts in bio-optical variables, we examined the variations in the biooptical variables in mesopelagic (250-300 m) and deep water (950-1000 m) values, i.e. at depths where little signal was anticipated and most profiles reached steady background values (Fig. 2a). The particulate backscattering and, to a lesser extent, the Chl $a$ fluorescence signals showed spikes which presumably reflect larger particles such as aggregates and zooplankton, motivating our examination of average values over $50 \mathrm{~m}$ ranges (250-300 and 950-1000 $\mathrm{m}$ depth layers) for the assessment of temporal drifts. As shown in Fig. 2a and quantified in Table 2, for most of their deployment periods, all four bio-profilers exhibited no significant temporal drift of these deep values except for bio-profiler \#1, for which high and erratic values of Chl $a$ and $b_{\text {bp }}$ began to occur after profile \#300 both at depth (Fig. 2a) and throughout the water column (Fig. 3c and e). We consider this to be caused by bio-fouling and do not use these data in any subsequent analysis (this loss of signal fidelity was one of the motivations for including periodic deep profiles in the subsequent three bio-profiler deployments, as a means of retarding fouling). In contrast, the high-fluorescence chlorophyll values found in mesopelagic waters from profiles $\sim \# 100$ to $\sim \# 170$ along bio-profiler \#1 trajectory appear to be real and to reflect the deep extension of high biomass occurrence at this time, as discussed further below (see also Fig. 3c). Consequently, this range of profiles was not taken into account for the drift calculation in Table 2. Overall, except for bio-profiler \#1, most of the bio-optical sensors showed a slight loss of sensitivity with time, as indicated by the negative slopes of the trend of their responses in the two considered depth layers (Table 2). Over the time course of the bio-optical sensor observations, these sensor drifts were small in comparison to the changes observed for surface bio-optical values, contributing less than $7 \%$ to either fluorescence or particulate backscattering. The only exception was for the bio-profiler \#2 $b_{\mathrm{bp}}$ sensor in the 250-300 m layer, for which drift appeared to have been larger (though of course changes at this depth range may also be oceanic) and reached up to $19 \%$ of the low surface $b_{\mathrm{bp}}$ values for this bio-profiler.

Fluorescence signals were also corrected for daytime quenching. This effect, which derives from the photoinhibition of phytoplankton by an excess of light (maximum at midday), decreases surface fluorescence (Falkowski and Kolber, 1995; Kiefer, 1973) and, if uncorrected, can produce a false impression of subsurface maxima in fluorescence derived chlorophyll profiles. We explain this correction and its evaluation in considerable detail in the following paragraphs, but note that none of the conclusions of the paper depend on these corrections because the same overall results are obtained if we use only Chl $a$ fluorescence signals collected at night. Our purpose in detailing the correction is to contribute to active discussion on the best way to use daylight Chl $a$ fluorescence data obtained from platforms which may not have as good night-time coverage as our floats (such as sensors deployed on seals, on standard ARGO 10-day profile interval missions, or on float missions that target co-measurement with daytime satellite ocean colour observations).

We defined the daytime profiles, potentially affected by quenching, as profiles acquired between $1 \mathrm{~h}$ after local sunrise time and $1 \mathrm{~h}$ after local sunset time in order to allow for dark acclimation, since the quenching effect could still persist after sunset (Sackmann et al., 2008). Daytime profiles from the four bio-profilers are shown to illustrate this effect (continuous lines in Fig. 2b, left panel). To correct this bias, we applied the method of Sackmann et al. (2008), which uses the particulate backscattering signal as a relative reference. For the sake of consistency with the other studies of this issue, we defined the mixed layer depth, MLD, as the depth where density increased by $0.02 \mathrm{~kg} \mathrm{~m}^{-3}$ relative to the density at $10 \mathrm{~m}$ (Park et al., 1998). Within the deeper half of the mixed layer (targeted to be below the depth of daytime quenching), we determined a mean value of the (relatively constant; see below) Chl $a$ fluorescence to $b_{\mathrm{bp}}$ ratio (at depth defined as $d_{F / b_{\mathrm{bp}}}$ ) and multiplied this ratio by the $b_{\mathrm{bp}}$ signal at this depth to retrieve the Chl $a$ fluorescence. Then, we multiplied this same ratio by the surface $b_{\mathrm{bp}}$ value to estimate unquenched surface $\mathrm{Chl} a$ fluorescence, and interpolated between these two depths to obtain the unquenched Chl $a$ fluorescence profile. This assumes that phytoplankton populations were not stratified within the density-defined mixed layer. This works particularly well for deep mixed layers (>50 m) which exhibit relatively constant Chl $a$ fluorescence $/ b_{\text {bp }}$ ratios (to within $\sim 10 \%$ ) in their deeper half. In less than $3 \%$ of the daytime profiles, on average, we could not identify a region of uniform Chl $a$ fluorescence $/ b_{\mathrm{bp}}$ and 
a) Drifting assessment
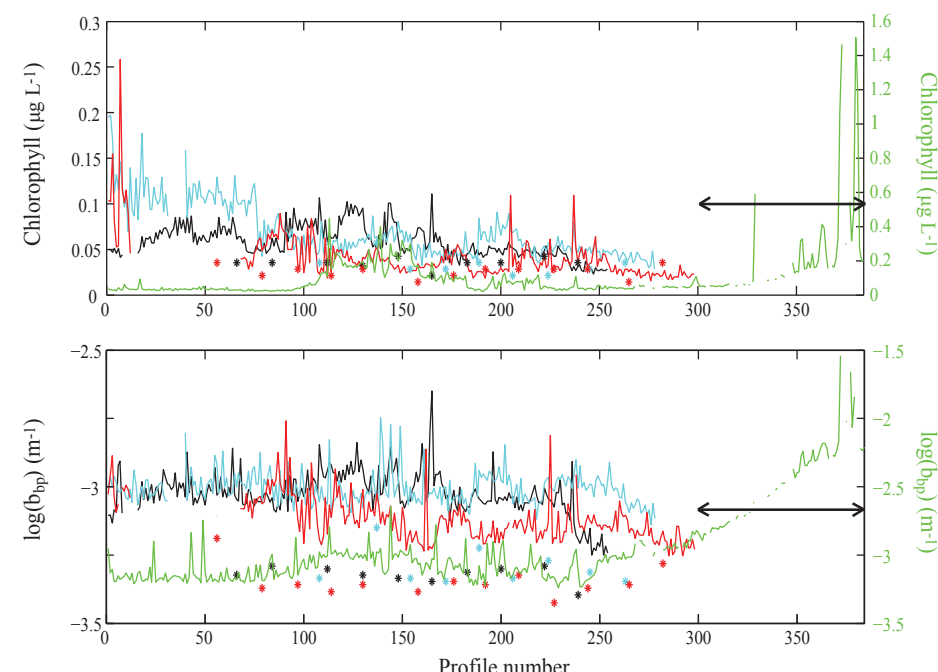

$$
\begin{aligned}
& \text { Mean value within the } \\
& \text { depth range [250-300] m } \\
& \text { Mean value within the } \\
& \text { depth range [950-1000] m } \\
& \text { * } \text { Bio-profiler \#1 } \\
& \bar{*} \text { Bio-profiler \#2 } \\
& \hline \text { * Bio-profiler \#3 } \\
& \text { Bio-profiler \#4 }
\end{aligned}
$$

b) Quenching assessment
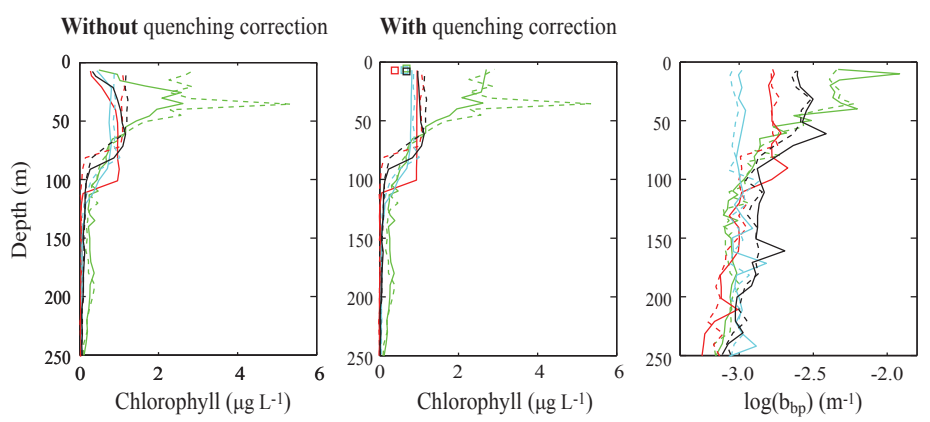

- - - Bio-profiler \#1 - night (\#141)

- Bio-profiler \#1 - day (\#142)

- - Bio-profiler \#2 - night (\#159)

- Bio-profiler \#2 - day (\#160)

- Bio-profiler \#3 - night (\#271)

Bio-profiler \#3 - day (\#272)

- - - Bio-profiler \#4 - night (\#18)

- Bio-profiler \#4 - day (\#19)

c) Comparison to KEOPS2 shipboard observations
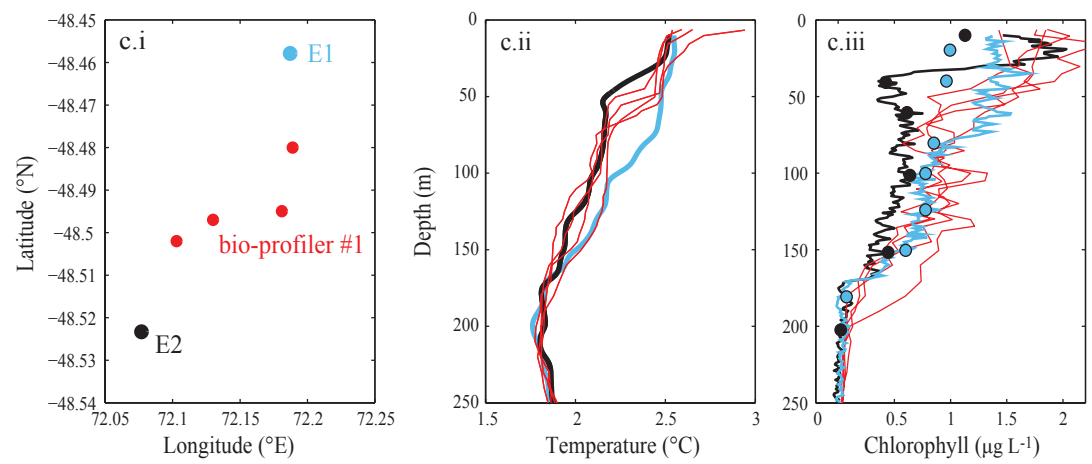

Figure 2. (a) Assessment of bio-optical sensor stability from temporal evolution of chlorophyll and particulate backscattering values averaged over two depth ranges: 250-300 (lines) and 950-1000 m (stars). Arrows indicate profiles considered to be affected by bio-fouling, which were not used in further analysis. (b) Illustration of quenching corrections, showing pairs of successive night/day profiles (day: continuous lines; night: dashed lines). Panels show, for each bio-profiler, chlorophyll profiles without quenching correction (left), chlorophyll profiles with quenching correction (middle), and associated particulate backscattering profiles (right). Squares in the middle panel represent threshold values of the lowest surface chlorophyll concentration for the night profiles of each bio-profiler (\#1: 0.7; \#2: 0.4; \#3: 0.65 ; \#4: $0.7 \mu \mathrm{g} \mathrm{L}-1$ ). These thresholds were used to flag day profiles with surface chlorophyll concentrations still below them after the quenching correction (see Table 3 and Figs. 7 (squares), 8 (red circles), and 10 (squares)), for which quenching might have been under-corrected. (c) Comparison of bio-profiler \#1 fluorescence Chl $a$ estimates to shipboard results obtained by the KEOPS2 project: (c.i) location of KEOPS2 stations E1 (blue symbols) and E2 (black symbols) along a quasi-Lagrangian track followed by bio-profiler \#1 (red symbols); (c.ii) temperature profiles showing similar structures of the ship and bio-profiler sampled water columns; (c.iii) fluorescence profiles (lines) showing that the bio-profiler provided similar fluorescence results to the ship CTD-mounted sensor, and that both exhibited complex relationships to Niskin bottle total chlorophyll $a$ sample values (dots; see text for further discussion). 
a)
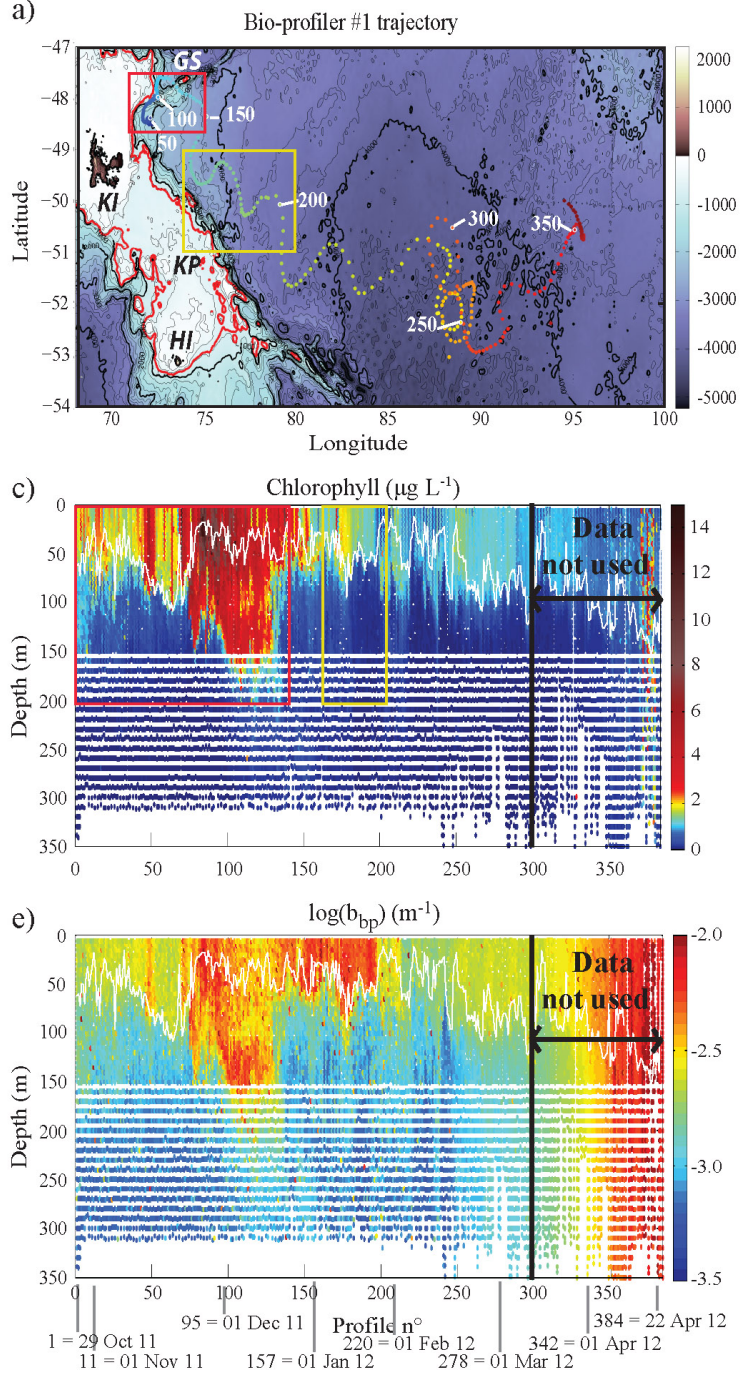

b)

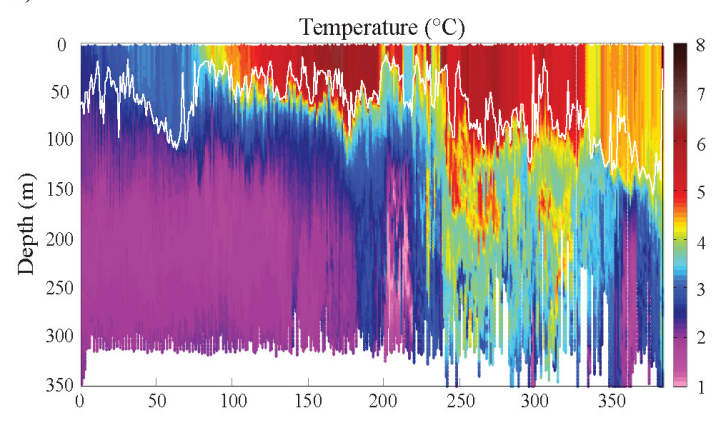

d)

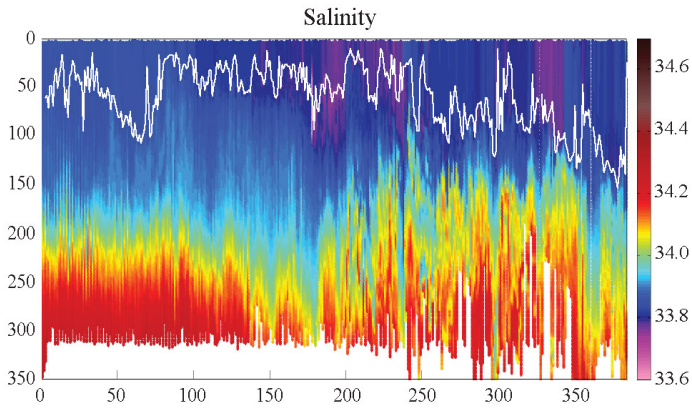

f)

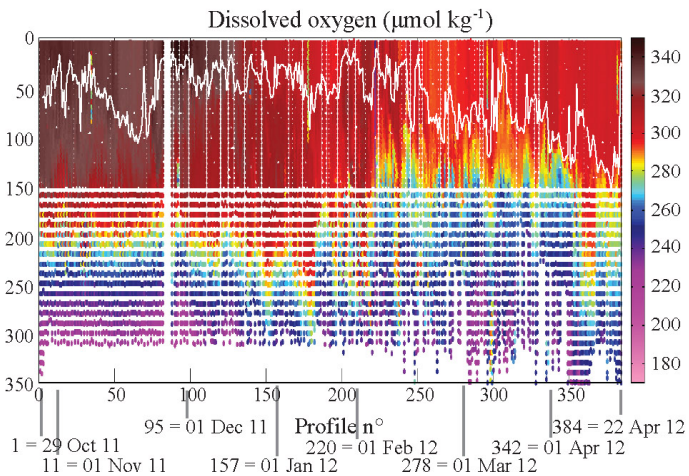

Figure 3. Bio-profiler \#1 observations. (a) Bio-profiler \#1 trajectory over the bathymetry, with each point representing a depth profile and the colour of the points changing from blue to red over time (dates are shown below the bottom plots). The $700 \mathrm{~m}$ isobath is represented by the red line contour. KI: Kerguelen Islands; KP: Kerguelen Plateau; HI: Heard Island; GS: Gallieni Spur. (b-f) Evolution of hydrological parameters along the float trajectory: (b) temperature $\left({ }^{\circ} \mathrm{C}\right)$, (c) chlorophyll $\left(\mu \mathrm{g} \mathrm{L}^{-1}\right)$, (d) salinity (unitless), (e) particulate backscattering $\left(b_{\mathrm{bp}} ; \log\right.$ scale; $\left.\mathrm{m}^{-1}\right)$, and (f) dissolved oxygen $\left(\mu \mathrm{mol} \mathrm{kg}^{-1}\right)$. The white line represents the mixed layer depth. Red and yellow rectangles refer to areas of high and moderate chlorophyll used in Fig. 10 and discussed in Sect. 4.2.

apply the quenching correction; consequently, these profiles were not used further.

The greater spikiness of the $b_{\mathrm{bp}}$ profiles in comparison to those of fluorescence (as illustrated in Fig. 2b, right panels) means that this quenching correction introduces some noise into the daytime chlorophyll estimates. In principle, this could be filtered or smoothed, but the low $10 \mathrm{~m}$ vertical resolution of the observations made this rather uncertain, and so we have used the unfiltered observations throughout this paper (except in Fig. 12f below, where we show medianfiltered particulate backscattering profiles for the sake of visual clarity). Before making the correction we verified that the $b_{\text {bp }}$ surface value was not "spiked" (by checking that the surface value did not exceed more than $\pm 50 \%$ of the $b_{\mathrm{bp}}$ value at the depth $d_{F / b_{\mathrm{bp}}}$ ). This threshold was defined after assessing the backscatterometer precision (using the coefficient of variation of $b_{\mathrm{bp}}$, i.e. the ratio of the standard deviation to the mean) between 500 and $1000 \mathrm{~m}$ depth of $14 \pm 4 \%$ on average. If the surface $b_{\mathrm{bp}}$ value was considered as spiked (less than $4 \%$ of the daytime $b_{\mathrm{bp}}$ profiles, except for bioprofiler \#4, for which it reached $9 \%$ ), the test was done with the second depth value, until a "non-spiked" value was found, and the value was then extrapolated to the surface.

The effects of the quenching correction on our selected chlorophyll profiles are shown in Fig. 2b (middle panels, continuous lines), and summary statistics for all the profiles 
a)

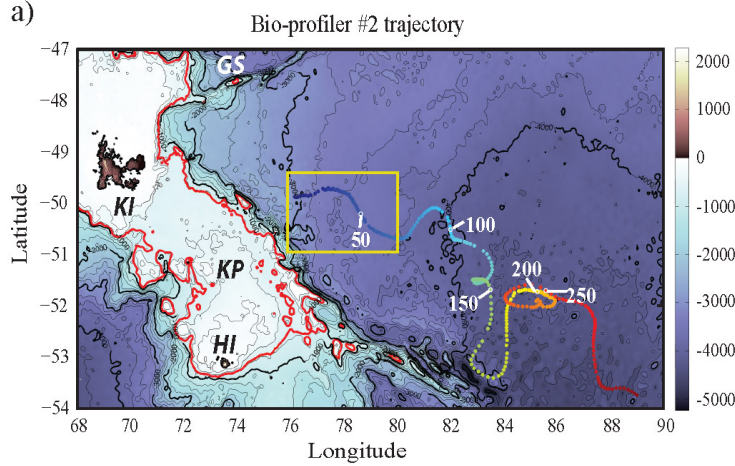

c)
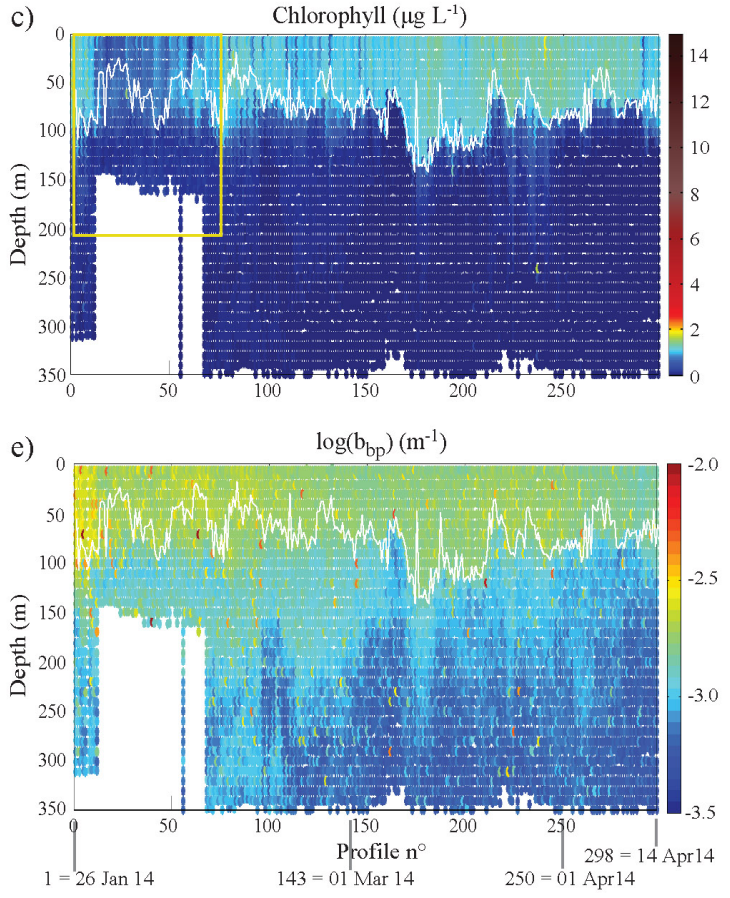

b)

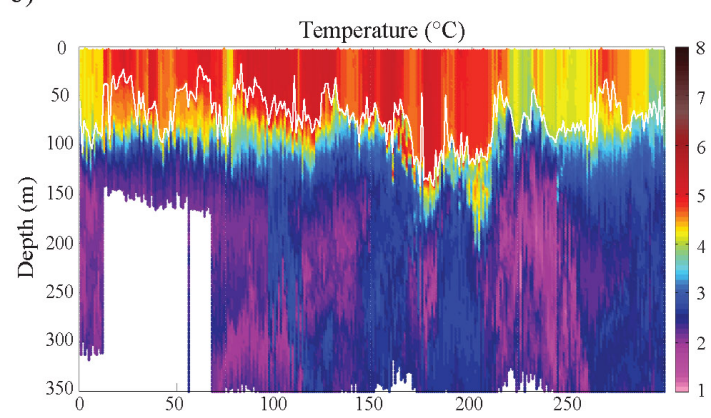

d)

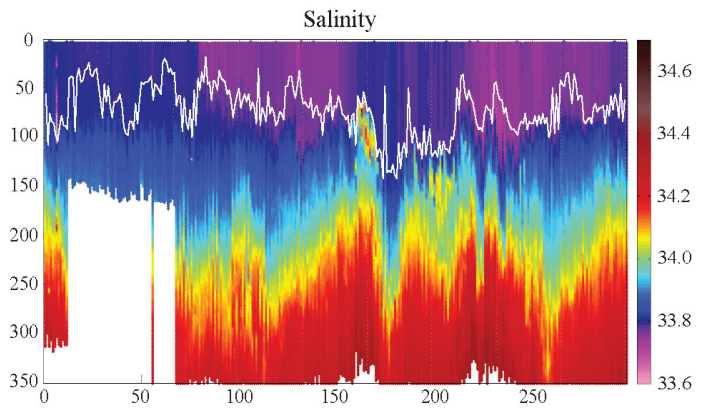

f)

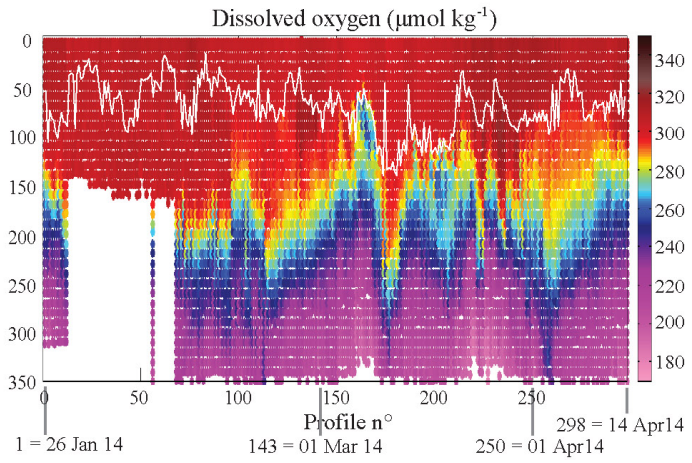

Figure 4. Same as Fig. 3 but for bio-profiler \#2.

are provided in Table 3. Without the correction, on average, more than $70 \%$ of the daytime profiles exhibited a subsurface maximum exceeding $60 \%$ of the surface value - defined after assessing the fluorometer error (coefficient of variation of Chl $a$ concentration) between 250 and $300 \mathrm{~m}$ depth and between 500 and $1000 \mathrm{~m}$ depth of $22 \pm 10 \%$ on average. After applying the quenching correction method, the number of daytime profiles exhibiting a subsurface maximum exceeding $60 \%$ of the surface value was reduced to very similar levels to those observed in the night-time profiles, although slightly higher (by $21 \%$ on average), indicating, with the fact that these daytime subsurface maxima occurred mostly below the MLD, that the correction was largely successful. Notably, for the total data set, after quenching correction, less than $11 \%$ of the profiles exhibited a deep maximum exceeding $100 \%$ of the surface value (Table 3 ), and these profiles were primarily located in a restricted region near the Gallieni Spur, as discussed further in the Results section.

Even after our quenching correction, $10 \%$ of the corrected daytime profiles (on average for all four bio-profilers) still exhibited significant decrease in the $\mathrm{Chl} a$ fluorescence in the surface layer. We were not able to conclude whether these decreases were due to an incomplete quenching correction or whether they were true features, given that $\sim 14 \%$ of the night profiles on average exhibited subsurface values at least $60 \%$ higher than the surface values. Consequently, we defined a threshold surface value for each bio-profiler, defined as a slightly lower value than the minimum surface value reached during night profiles (see caption and the squares in Fig. 2b, middle panel) and we flagged all the corrected daytime profiles that had a surface value lower than this threshold as potentially arising from incomplete correction of quenching. These distinctions between night, daytime, and 
a)

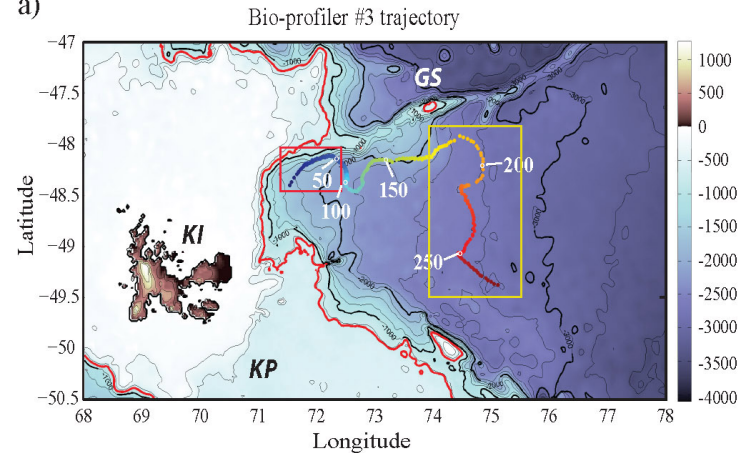

c)

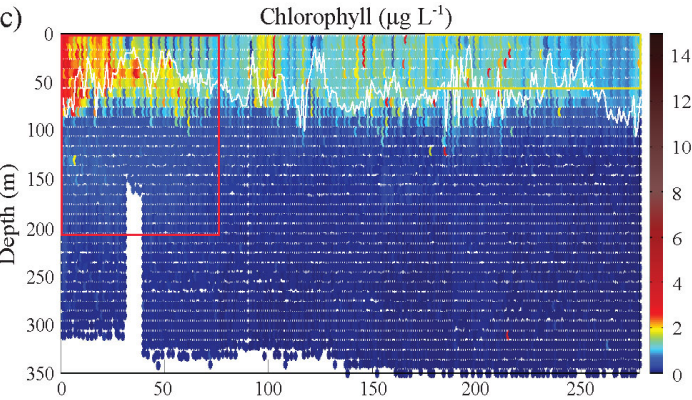

e)

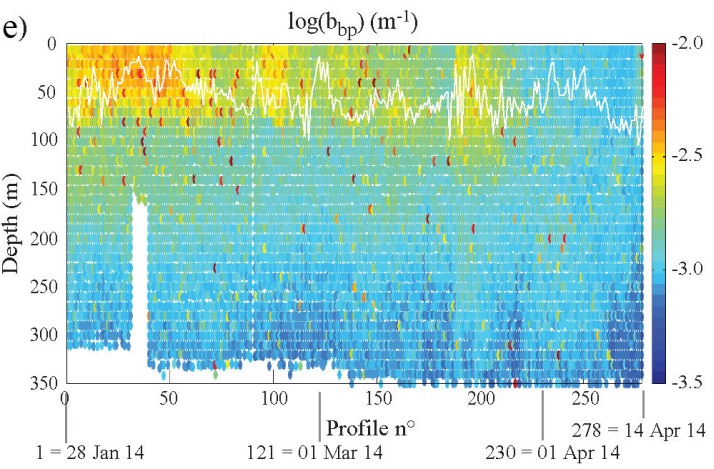

b)

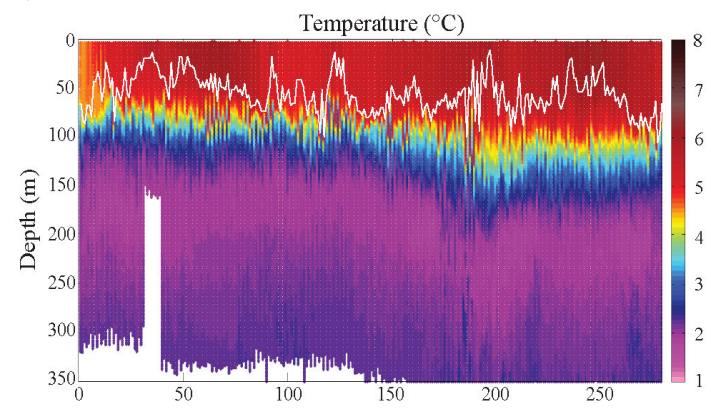

d)

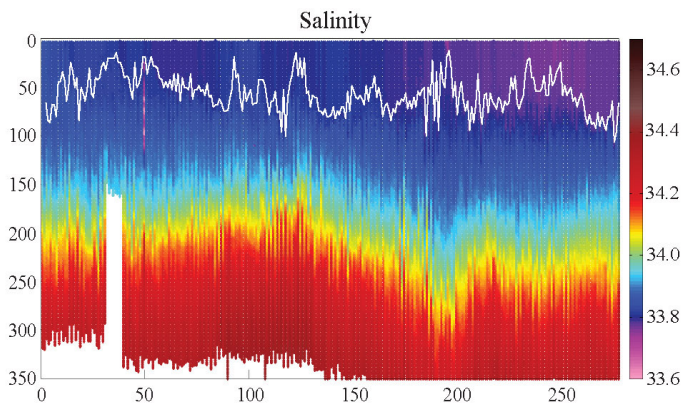

f)

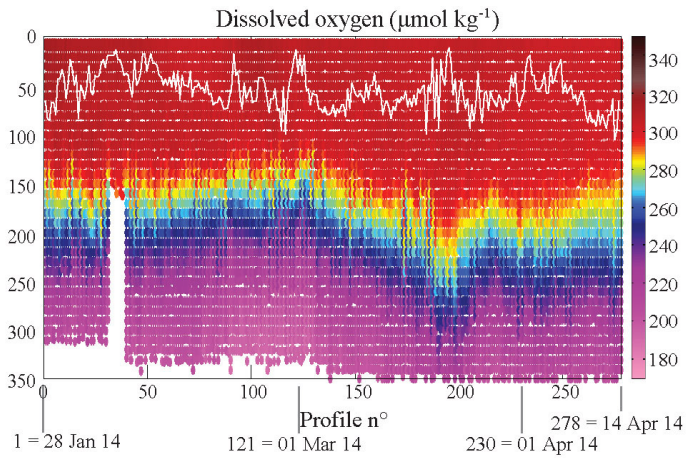

Figure 5. Same as Fig. 3 but for bio-profiler \#3.

flagged profiles are illustrated in Figs. 7, 8, and 10, and further discussed in the Results and Discussion sections below. Note that, using a different quenching correction method, Biermann et al. (2015) recently observed similar features and statistics in fluorescence profiles collected by sensors on southern elephant seals during austral summer in the vicinity of the Kerguelen Islands.

Finally, we emphasise that the bio-optical measures of chlorophyll and particulate backscattering are based on laboratory calibrations that are not specific to Southern Ocean phytoplankton or particle properties. This means that, while interpretation of local variations is reasonably straightforward, quantitative comparisons to other observations are much more uncertain (except perhaps in the future for other serial numbers of these sensors, calibrated in the same limited way). For the three bio-profilers deployed in 2014, no ancillary shipboard measurements are available to evaluate this issue, but in 2011 some chlorophyll samples were col- lected by the KEOPS2 science team that allow for limited evaluation of the bio-profiler \#1 calibration.

Bio-profiler \#1 was deployed into a semi-permanent meander of the Polar Front, which the KEOP2 programme examined as a Lagrangian time series following surface drifters. As shown in Fig. 2c, the first and second stations in the meander (E1 CTD-27 on 29 October 2011 at 22:46 LT and E2 CTD-43 on 1 November 2011 at 12:00 LT) bracketed the locations of the first 11 autonomous bio-profiler \#1 profiles (Fig. 2c.i). The bio-profiler \#1 temperature profiles are intermediate between the ship results (Fig. 2c.ii), with the variations in temperature profiles mainly driven by vertical motions associated with internal waves (Park et al., 2014b). In Fig. 2c.iii, the KEOPS2 shipboard fluorescence results are displayed after linear calibration to high-pressure liquid chromatography (HPLC) total chlorophyll $a$ results from below $40 \mathrm{~m}$ depth (below the depth of non-photochemical quenching). The data reveal two important features: (1) good 

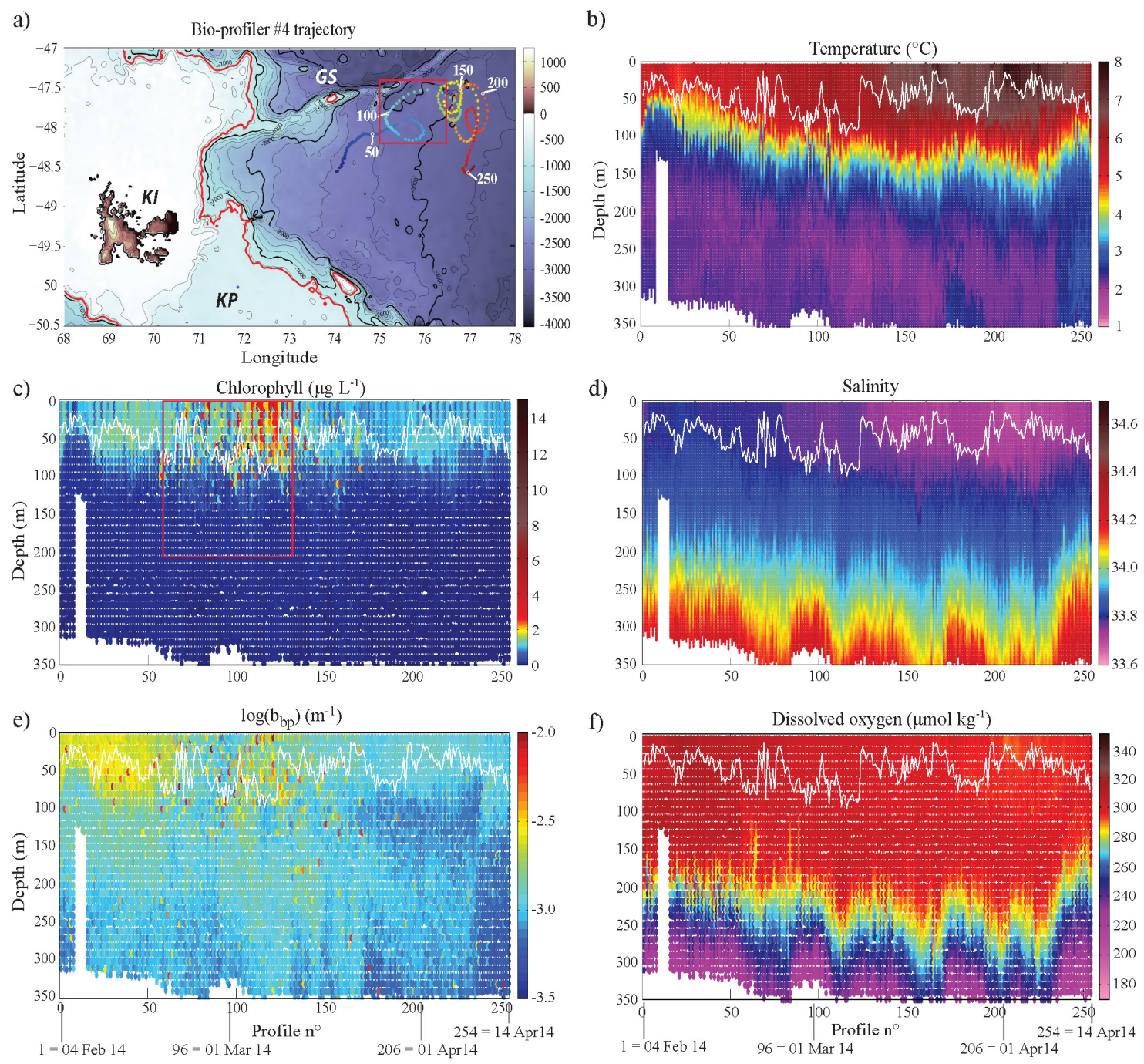

f)

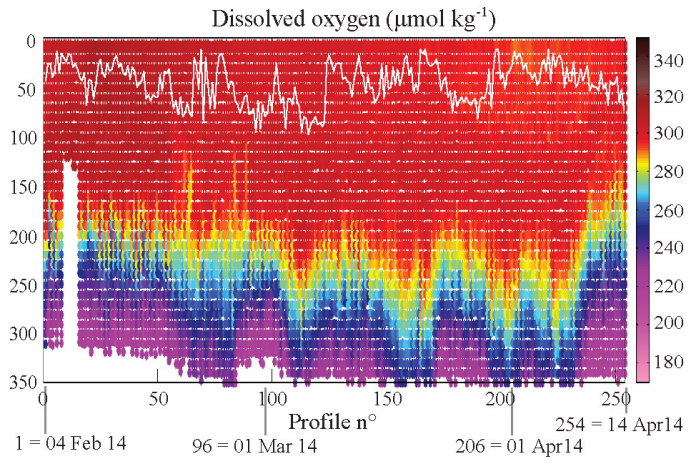

Figure 6. Same as Fig. 3 but for bio-profiler \#4.

fits achieved below $40 \mathrm{~m}$ do not extend to the surface - where fluorescence / chlorophyll $a$ ratios were higher than at depth, apparently as a result of community composition variations with depth (see also Lasbleiz et al., 2014), and (2) the bioprofiler \#1 fluorescence data displayed similar characteristics and good accord with the shipboard results. In light of the limited available data, a non-linear calibration of fluorescence to chlorophyll $a$ was not pursued, and no adjustments were made to the laboratory bio-profiler calibration.

These variations in fluorescence / chlorophyll $a$ ratios within individual CTD casts in the shipboard observations serve as a strong reminder that fluorescence is an imperfect proxy for chlorophyll $a$ concentrations, owing to variations with phytoplankton community structure, physiology, and other effects (e.g. Babin et al., 1996; Cullen, 1982; Suggett et al., 2011). Thus, when interpreting our sensor records, as with any bio-optical sensor results, this must be kept in mind, and over-interpreting small variations in fluorescence as nec- essarily resulting from variations in chlorophyll or phytoplankton biomass must be avoided.

\subsection{Satellite data sources}

We used satellite products to provide physical and biological context for the bio-profiler trajectories, including the effectiveness of their sampling of high-biomass waters downstream of Kerguelen. The images of surface chlorophyll concentrations shown in Fig. 1 to provide context for the plume sampling achieved by the bio-profilers are the CLS SSALTO/DUACS $4 \mathrm{~km}$ daily product derived from NASA MODIS-Aqua observations (Fig. 1), without taking into account that this algorithm may underestimate chlorophyll in low-chlorophyll waters south of Australia (Johnson et al., 2013).

To better understand the observed bio-profiler trajectories, we calculated expected movements based on geostrophic 
Table 2. Drift assessment of the bio-profilers over their lifetime within the [250-300] $\mathrm{m}$ and [950-1000] $\mathrm{m}$ depth layers.

\begin{tabular}{|c|c|c|c|}
\hline \multicolumn{4}{|c|}{ Chlorophyll concentration drift within the $[250-300] \mathrm{m}$ depth layer } \\
\hline \# & $\begin{array}{r}\text { Mean slope } \\
\left(\mu \mathrm{L} \mathrm{L}^{-1} \text { profile }^{-1}\right)\end{array}$ & $\begin{array}{l}\text { Mean absolute } \\
\operatorname{drift}^{\mathrm{a}}\left(\mu \mathrm{g} \mathrm{L}^{-1}\right)\end{array}$ & $\begin{array}{l}\text { Mean drift relative to the } \\
\text { mean surface Chl } a \text { concentration }\end{array}$ \\
\hline $1^{\mathrm{c}}$ & $8.4050 \mathrm{E}-5$ & 0.0252 & $+1 \%$ \\
\hline 2 & $-1.7832 \mathrm{E}-4$ & -0.0531 & $-5 \%$ \\
\hline 3 & $-2.8722 \mathrm{E}-4$ & -0.0798 & $-6 \%$ \\
\hline 4 & $-1.1976 \mathrm{E}-4$ & -0.0304 & $-3 \%$ \\
\hline \multicolumn{4}{|c|}{ Chlorophyll concentration drift within the $[950-1000] \mathrm{m}$ depth layer } \\
\hline \# & $\begin{array}{r}\text { Mean slope } \\
\left(\mu \mathrm{g} \mathrm{L}^{-1} \text { profile }^{-1}\right)\end{array}$ & $\begin{array}{l}\text { Mean absolute } \\
\operatorname{drift}^{\mathrm{a}}\left(\mu \mathrm{g} \mathrm{L}^{-1}\right)\end{array}$ & $\begin{array}{l}\text { Mean drift relative to the } \\
\text { mean surface Chl } a \text { concentration }\end{array}$ \\
\hline 1 & - & - & - \\
\hline 2 & -2.1917 E-6 & -0.0007 & $<-1 \%$ \\
\hline 3 & $-9.0120 \mathrm{E}-5$ & -0.0251 & $-2 \%$ \\
\hline 4 & 1.2438 E-5 & 0.0032 & $<+1 \%$ \\
\hline \multicolumn{4}{|c|}{ Particulate backscattering drift within the $[250-300] \mathrm{m}$ depth layer } \\
\hline \# & $\begin{array}{l}\text { Mean slope } \\
\qquad\left(\mathrm{m}^{-1}\right)\end{array}$ & $\begin{array}{r}\text { Mean absolute } \\
\operatorname{drift}^{\mathrm{a}}\left(\mathrm{m}^{-1}\right)\end{array}$ & $\begin{array}{l}\text { Mean drift relative to the } \\
\text { mean surface } b_{\mathrm{bp}}^{\mathrm{d}}\end{array}$ \\
\hline $1^{\mathrm{c}}$ & 1.1625 E-6 & 3.4876 E-04 & $+11 \%$ \\
\hline 2 & -1.1613 E-6 & -3.4608 E-04 & $-19 \%$ \\
\hline 3 & -1.9682 E-7 & -5.4716 E-05 & $-2 \%$ \\
\hline 4 & $-6.7301 \mathrm{E}-7$ & $-1.7094 \mathrm{E}-04$ & $-10 \%$ \\
\hline \multicolumn{4}{|c|}{ Particulate backscattering drift within the [950-1000] m depth layer } \\
\hline \# & $\begin{array}{r}\text { Mean slope } \\
\left(\mathrm{m}^{-1}\right)\end{array}$ & $\begin{array}{r}\text { Mean absolute } \\
\operatorname{drift}^{\mathrm{a}}\left(\mathrm{m}^{-1}\right)\end{array}$ & $\begin{array}{l}\text { Mean drift relative to the } \\
\text { mean surface } b_{\mathrm{bp}}^{\mathrm{d}}\end{array}$ \\
\hline 1 & - & - & - \\
\hline 2 & $-2.2931 \mathrm{E}-7$ & -6.8335 E-05 & $-4 \%$ \\
\hline 3 & -4.4734 E-7 & -1.2436 E-04 & $-6 \%$ \\
\hline 4 & -2.0227 E-7 & -5.1378 E-05 & $-3 \%$ \\
\hline
\end{tabular}

currents estimated from satellite altimetry using the multisatellite global product Delayed Time Maps of Absolute Dynamic Heights (DT-MADT) developed by the CNES/CLS Aviso project (www.aviso.oceanobs.com). This product has 1-week temporal and $1 / 3^{\circ}$ spatial resolutions, and was used to compute Lagrangian trajectories to produce a diagnostic for eddy retention (d'Ovidio et al., 2013; Fig. 12b) and water origin and age (d'Ovidio et al., 2015; Fig. 11). Eddy retention is a measure of how much time a synthetic water parcel has been recirculating within an eddy core. Long-lived and coherent eddies are characterised by water parcels with high values of retention (measured in days since a water parcel has been entrained by an eddy), whereas recently formed eddies or eddies that exchange strongly with surrounding regions have low retention values. Following d'Ovidio et al. (2015) and Sanial et al. (2014), we used backtracking of virtual wa- ter parcels (from the bio-profiler profile locations) to compute how long ago (water age) and at which latitude (water origin) the sampled parcels had been in contact with the Kerguelen Plateau (defined as the $700 \mathrm{~m}$ isobath, as shown in red in Figs. 3a, 4a, 5a, and 6a). Figure 11a and c, adapted from d'Ovidio et al. (2015), display example maps of the calculated daily snapshots of these water ages and water origins. For each pixel in these maps, virtual water parcels were backtracked for 100 days. They are shown as white pixels on the maps if during that time they never touched the Kerguelen Plateau (bathymetry shown in grey on the map), and otherwise are coloured for the time between the contact with the plateau and the day of the map computation (water age, Fig. 11a) and the latitude of the last contact with the plateau stored (water origin, Fig. 11c). These same computations were performed for each location sampled by the 
Areas where subsurface chlorophyll maximum exceeds the surface content by more than $60 \%$
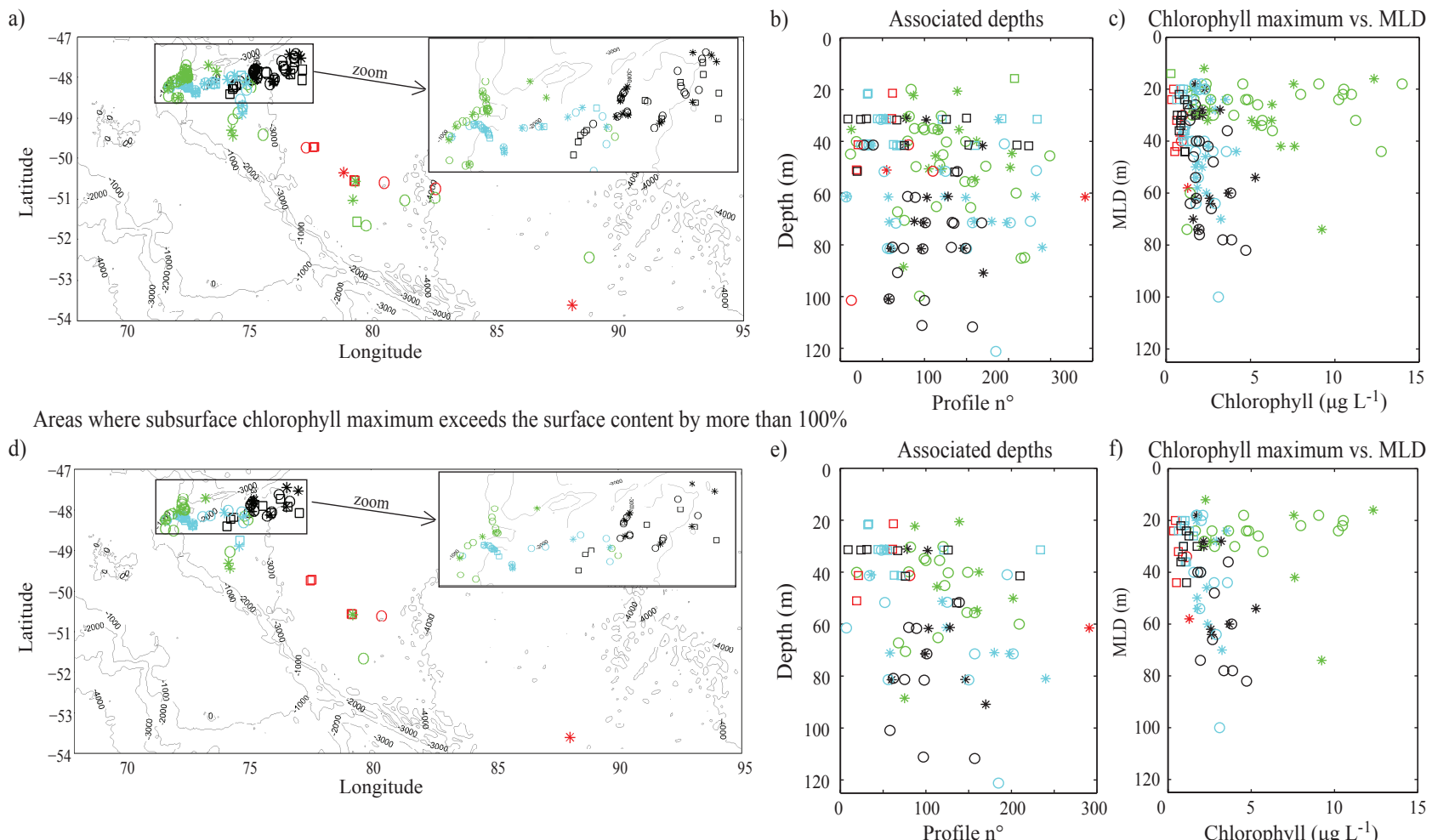

f) Chlorophyll maximum vs. MLD

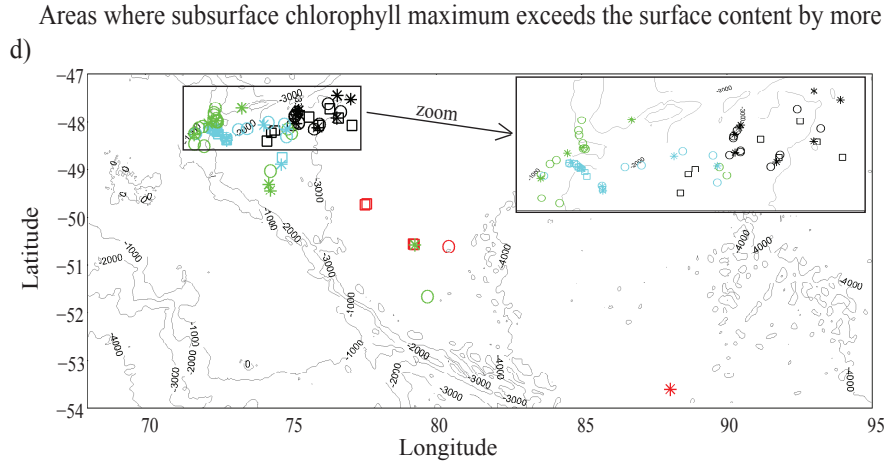

Bio-profiler \#1

* Night profiles
Bio-profiler \#2

Corrected day profiles
Bio-profiler \#3

Bio-profiler \#4

Corrected day profiles which still exibit,

$\square$ in the surface layer, a large concentration decrease toward low surface values

Figure 7. Characteristics of subsurface chlorophyll maxima occurring at depths greater than the mixed layer depth and exceeding the surface content by more than $60 \%$ (top) and $100 \%$ (bottom). (a, d) Geographical areas where these subsurface Chl $a$ maxima occur with an expanded view for the Gallieni Spur region. (b, e) Associated depths of these subsurface Chl $a$ maxima along the bio-profiler trajectories (i.e. vs. profile numbers). (c, f) Relationship between the amplitude of these Chl $a$ maxima (in $\mu \mathrm{g} \mathrm{L}^{-1}$ ) and the mixed layer depth (MLD, in m). Symbols: stars refer to night profiles, circles to day profiles, and squares to flagged day profiles (i.e. which still exhibit, in the surface layer, a large concentration decrease toward low surface values that indicates the possibility of incomplete quenching correction; see definition in the caption of Fig. 2b).

bio-profilers in order to compare the water ages and origins with their measured chlorophyll inventories.

\section{Results}

\subsection{Coverage of the plume}

The drifts of the bio-profilers provided coverage of a large portion of the elevated biomass plume (Fig. 1), from near the Kerguelen Plateau to more than 700 nautical miles downstream $\left(71\right.$ to $\left.95^{\circ} \mathrm{E}\right)$ and nearly 400 nautical miles from north to south $\left(47.5\right.$ to $\left.54^{\circ} \mathrm{S}\right)$, thereby spanning waters of the Polar Frontal and Antarctic zones (Orsi et al., 1995; Park et al., 2008b; Sokolov and Rintoul, 2009). Unfortunately, this breadth of spatial coverage of the plume did not extend to full temporal seasonal coverage, and this is important to keep in mind given the strong seasonal cycle of biomass accumulation (Trull et al., 2015; Blain et al., 2007; Mongin et al., 2008). As shown in these images, the 2011 bio-profiler covered the period of highest biomass accumulation, while the 2014 deployments occurred after this seasonal peak and thus sampled the system during its senescence (to illustrate these prior conditions, Fig. 1 also includes biomass distribution images from late 2013, before the launch of the three bioprofilers in early 2014). Thus, the profilers obtained some seasonal context for the central portion of the plume (which was sampled well in 2011 by bio-profiler \#1 in spring and summer and again by bio-profilers \#2 and \#3 in summer and autumn). However, sampling of the north-eastern portion of the downstream plume (north of the Polar Front) was 
a)
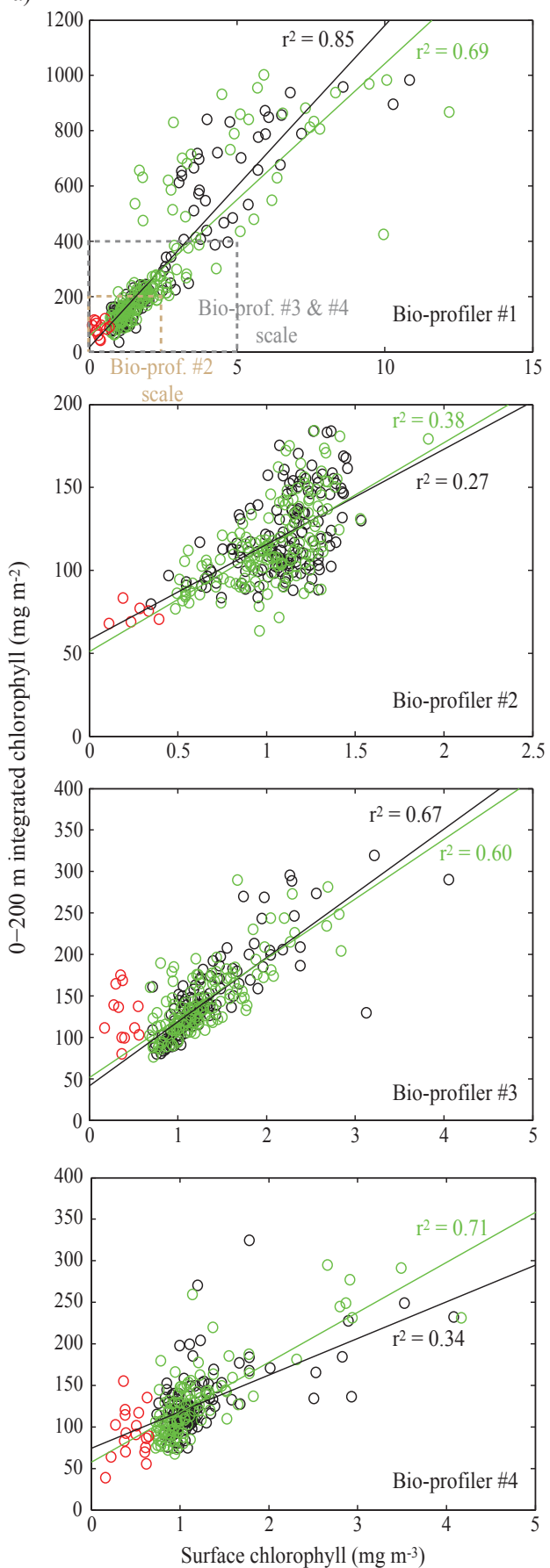

$$
\begin{aligned}
& \text { Night profiles } \\
& \text { Corrected day profiles which still exibit, } \\
& \text { in the surface layer, a large concentration } \\
& \text { decrease toward low surface values }
\end{aligned}
$$

b)
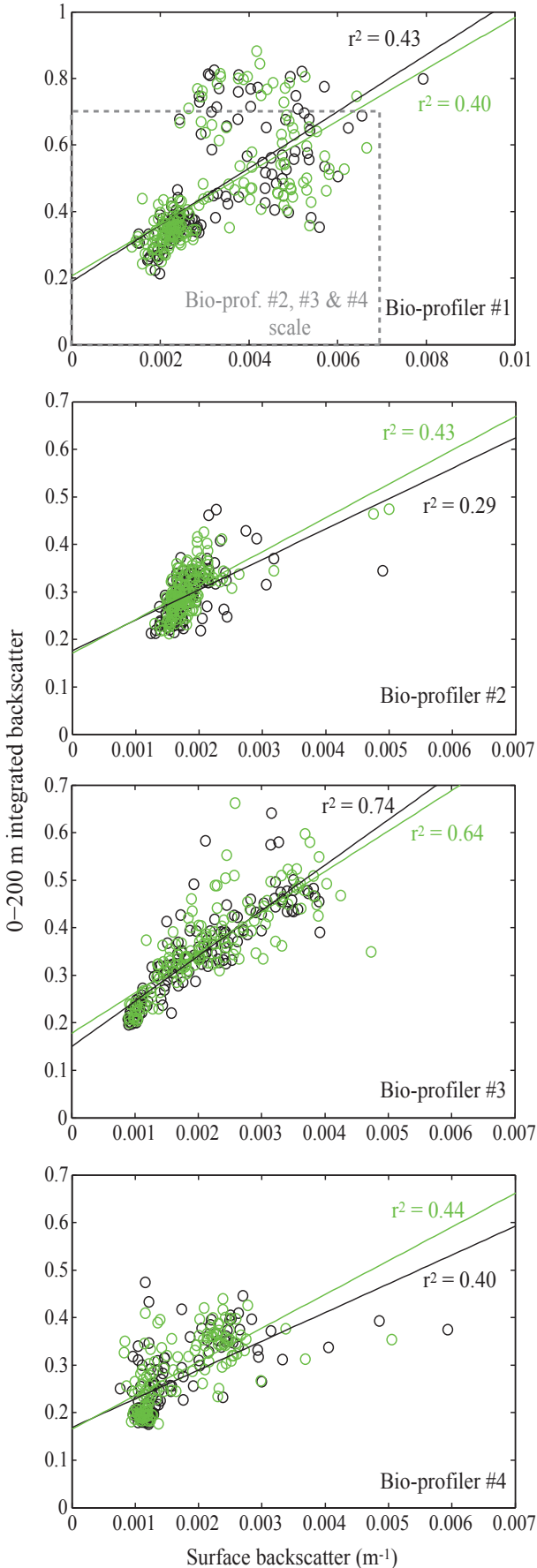

$\bigcirc$ Night profiles $\bigcirc$ Corrected day profiles

Figure 8. (a) Surface chlorophyll concentrations (in $\left.\mathrm{mg} \mathrm{m}^{-3}\right)$ compared to chlorophyll inventories $\left(0-200 \mathrm{~m}\right.$; in $\mathrm{mg} \mathrm{m}^{-2}$ ), for each bioprofiler. (b) Surface particulate backscattering $\left(\mathrm{m}^{-1}\right)$ compared to particulate backscattering inventories $(0-200 \mathrm{~m})$, for each bio-profiler. Note that scales are slightly larger for bio-profiler \#1 than for the others; the dashed rectangles in upper plots indicate the scales used for the other bio-profilers. Night profiles (black circles), day profiles (green circles), and potentially quenching under-corrected day profiles (red circles, flagged as defined in the caption of Fig. 2b) are distinguished. Correspondingly, the green and black lines refer to the linear regression of day and night profiles and their associated correlation coefficients, $r^{2}$. 
Table 3. Fluorescence quenching corrections and subsurface chlorophyll maxima statistics.

\begin{tabular}{|c|c|c|c|c|}
\hline Individual bio-profiler statistics & $\# 1$ & $\# 2$ & \#3 & \#4 \\
\hline Fluorescence profiles collected & 384 & 298 & 278 & 254 \\
\hline Fluorescence profiles usable & 300 & 298 & 277 & 254 \\
\hline Night-time profiles & 129 & 143 & 133 & 119 \\
\hline Daytime profiles & 171 & 155 & 144 & 135 \\
\hline \multicolumn{5}{|l|}{ Night-time profiles with subsurface maxima ${ }^{a}$} \\
\hline total/within the ML/below the ML & $17 / 5 / 12$ & $3 / 1 / 2$ & $24 / 9 / 15$ & $25 / 14 / 11$ \\
\hline (\% of night-time profiles) & $(13 / 4 / 9) \%$ & $(2 / 1 / 1) \%$ & $(18 / 7 / 11) \%$ & $(21 / 12 / 9) \%$ \\
\hline \multicolumn{5}{|l|}{ Daytime profiles with subsurface maxima ${ }^{a}$} \\
\hline before correction total/within the ML/below the ML & $142 / 62 / 80$ & $93 / 55 / 38$ & $105 / 48 / 57$ & $95 / 40 / 55$ \\
\hline ( $\%$ of daytime profiles) & $(83 / 36 / 47) \%$ & $(60 / 35 / 25) \%$ & $(73 / 33 / 40) \%$ & $(70 / 30 / 40) \%$ \\
\hline $\begin{array}{l}\text { Quenching corrected profiles (and among them, } \\
\text { number of corrected profiles which still exhibit } \\
\text { low surface values }{ }^{\mathrm{c}} \text { ) }\end{array}$ & $170(22)$ & $155(6)$ & $139(12)$ & $127(18)$ \\
\hline \multicolumn{5}{|l|}{ Daytime profiles with subsurface maxima ${ }^{a}$} \\
\hline after correction total/within the ML/below the ML & $40 / 0 / 40$ & $10 / 1 / 9$ & $32 / 3 / 29$ & $40 / 9 / 31$ \\
\hline (\% of corrected day profiles) & $(24 / 0 / 24) \%$ & $(6 / 0 / 6) \%$ & $(23 / 2 / 21) \%$ & $(31 / 7 / 24) \%$ \\
\hline \multicolumn{5}{|l|}{ Total night and corrected day profiles with moderate } \\
\hline subsurface maxima ${ }^{a}$ total/within the ML/below the ML & $57 / 5 / 52$ & $13 / 2 / 11$ & $56 / 12 / 44$ & $65 / 23 / 42$ \\
\hline (\% of night and corrected day profiles) & $(19 / 2 / 17) \%$ & $(4 / 1 / 3) \%$ & $(20 / 4 / 16) \%$ & $(26 / 9 / 17) \%$ \\
\hline \multicolumn{5}{|l|}{ Total night and corrected day profiles with large } \\
\hline subsurface maxima $^{\mathrm{b}}$ total/within the ML/below the ML & $32 / 1 / 31$ & $6 / 0 / 6$ & $36 / 5 / 31$ & $45 / 15 / 30$ \\
\hline (\% of night and corrected day profiles) & $(10 / 0 / 10) \%$ & $(2 / 0 / 2) \%$ & $(13 / 2 / 11) \%$ & $(18 / 6 / 12) \%$ \\
\hline
\end{tabular}

${ }^{\text {a }}$ Subsurface values exceeding surface values by more than $60 \%$. ${ }^{\mathrm{b}}$ Subsurface values exceeding surface values by more than $100 \%$. $^{\mathrm{c}}$ For some corrected profiles, a large decrease in the chlorophyll concentration still occurred in the surface layer. These profiles are flagged in Figs. $2 \mathrm{~b}$ (squares), 7 (squares), and 8 (red circles). See the Method section and the caption of Fig. $2 \mathrm{~b}$ for more details.

achieved only in late summer and autumn (by bio-profiler \#4).

Bio-profiler \#1 in spring 2011 and bio-profiler \#3 in 2014 were deployed in the centre of the quasi-stationary cyclonic recirculation just east of the northern Kerguelen Plateau (d'Ovidio et al., 2015; Park et al., 2014a). Both bio-profilers exited this region to the north-east, tracking towards the Gallieni Spur, before transiting strongly southward near $74^{\circ} \mathrm{E}$. This southward transport has also been observed for surface drifters and appears to be associated with a persistent meander of the Polar Front (d'Ovidio et al., 2015; Park et al., 2014a). Thus bio-profilers \#1 and \#3 provide spring and summer perspectives respectively for these portions of the biomass plume (albeit in different years).

Bio-profiler \#2 was deployed further south, close to the region where the strong north-to-south transport portions of the bio-profilers \#1 and \#3 trajectories finished. Thus bio-profiler \#2 provided some overlap with the southern portion of the bio-profiler \#1 trajectory, before being carried the furthest south, where it explored cold waters close to the Williams Ridge, which extends to the south-east of Heard Island and terminates near the Fawn Trough (a gap in the plateau which permits the passage of much of the deep water eastward transport; Park et al., 2008b; 2014a). Waters in this region tend to exhibit archetypical high-nutrient, low-chlorophyll characteristics and were used as a reference station for iron non-fertilised waters during the KEOPS field programme in 2005 (Blain et al., 2007, 2008).

In contrast, bio-profiler \#4 was deployed at a similar latitude to bio-profilers \#1 and \#3 but further east, in particular east of the southward meander of the Polar Front which carried these others to the south. Bio-profiler \#4 remained in the northern portion of the plume throughout its deployment, drifting to the north-east roughly parallel to the shallow eastern Kerguelen Ridge before becoming trapped in a cyclonic eddy in which it obtained a time series of $\sim 100$ profiles (as discussed in detail below).

\subsection{Overview of observed oceanographic properties}

The bio-profilers return a large number of water column observations, making visualisation at the scale of individual profiles only possible for targeted issues. The simplest firstorder assessment is most easily done by presenting the results as along-trajectory sections. These are shown for all the observed variables for each bio-profiler in Figs. 3, 4, 5, and 6, and briefly described in the following paragraphs.

Bio-profiler \#1, launched in late October 2011 in the centre of the deep water recirculation just east of the Kerguelen Islands, initially encountered cold, well-oxygenated waters with moderate biomass $\left(T \sim 3{ }^{\circ} \mathrm{C}, \mathrm{O}_{2} \sim 330 \mu \mathrm{mol} \mathrm{kg}{ }^{-1}\right.$, $0.5 \mu \mathrm{g} \mathrm{L}^{-1}<\mathrm{Chl} a<2 \mu \mathrm{g} \mathrm{L}{ }^{-1}$; profiles $1-90$, November). It was then carried north-eastward across the Gallieni Spur, 
where it encountered warmer waters with extremely high biomass $\left(T \sim 5^{\circ} \mathrm{C}\right.$, chlorophyll up to nearly $\left.10 \mu \mathrm{g} \mathrm{L}{ }^{-1}\right)$, which satellite ocean colour animations suggest was being swept northward as a mix of waters from the northern and central regions of the Kerguelen Plateau (see the animation "bloom 2011" in the Supplement; Trull et al., 2015). During the subsequent southward transport, it crossed the Polar Front near $51.5^{\circ} \mathrm{S}$, as shown by the presence of a temperature minimum near $150 \mathrm{~m}$ depth $\left(T \sim 1{ }^{\circ} \mathrm{C}\right.$; profiles $\sim 200$ 220 , end of January). The shoaling of low dissolved oxygen layers in this region provides another indication of their Antarctic Zone oceanographic classification. Surface waters above this remnant winter water were relatively warm despite deep mixed layer depths $\left(\sim 100 \mathrm{~m}, T>6^{\circ} \mathrm{C}\right.$; profiles $\sim 240$ 330, February-March). Much of this warming is probably seasonal, as these waters were encountered in late summer, but the co-occurrence of somewhat elevated salinity $(\sim 33.8)$ suggests that flow of Polar Frontal Zone surface waters over the Antarctic waters was also involved. During the February bio-profiler transit, these waters exhibited only low to moderate chlorophyll biomass $\left(\sim 1.5 \mu \mathrm{gL}^{-1}\right)$, although satellite images suggest higher concentrations $\left(\sim 3 \mu \mathrm{g} \mathrm{L}^{-1}\right)$ were present earlier in December and January (see Fig. $1 \mathrm{~b}$ and c and the animation "bloom 2011" in the Supplement; Trull et al., 2015). The particulate backscattering signal reflected the chlorophyll evolution along most of the trajectory, except in January, when, as the chlorophyll levels decreased (from $>3$ to $\leq 2 \mu \mathrm{g} \mathrm{L}^{-1}$ ), $b_{\mathrm{bp}}$ remained high and constant $\left(-2.5 \mathrm{~m}^{-1} \leq \log \left(b_{\mathrm{bp}}\right) \leq-2.0 \mathrm{~m}^{-1}\right)$, suggesting detrital particles developed from the high chlorophyll biomass, or possibly a (relatively large) change in chlorophyll / particulate organic carbon ratio (Chl / POC) due to phytoplankton community composition. Finally, after 300 shallow profiles, biofouling of the fluorescence and particulate backscattering sensors marked the end of their utility, as shown by the occurrence of elevated and highly noisy values throughout the water column (see Fig. 3c and e).

Bio-profiler \#2, launched in late January 2014 south and east of the recirculation feature, initially encountered Polar Frontal Zone waters which were present further south in this region than during the 2011 year sampled by bioprofiler \#1. For approximately the first 150 profiles, these waters displayed relatively homogeneous, moderately warm temperatures $\left(4-5^{\circ} \mathrm{C}\right)$ that continued to warm to $\sim 6^{\circ} \mathrm{C}$ through February. The bio-profiler then transited much further south, briefly encountering waters with strong shoaling of subsurface salty, low-oxygen characteristics around profiles 160-170 $\left(S \sim 34.0-34.2, \mathrm{O}_{2} \sim 260 \mu \mathrm{mol} \mathrm{kg}^{-1}\right)$, and entered colder Antarctic waters, where it remained through profile $\sim 220$, at which time its return north brought it back into Polar Frontal Zone waters showing autumn cooling. Throughout its life, in comparison to bio-profiler \#1, only low- to moderate-biomass waters were encountered $\left(<1.5 \mu \mathrm{g} \mathrm{L}^{-1}\right)$, though these values were persistently above Southern Ocean HNLC background values $\left(<0.5 \mu \mathrm{g} \mathrm{L}^{-1}\right)$.
Within this range, the higher biomass values, which also extended over greater vertical extents $(\sim 100 \mathrm{~m})$, were found in the Antarctic waters (profiles 170-250, March-April). In contrast, the higher $b_{\mathrm{bp}}$ values were found at the beginning of the trajectory $\left(\log \left(b_{\mathrm{bp}}\right) \sim-2.5 \mathrm{~m}^{-1}\right)$, and their deep extent and high values compared to chlorophyll levels suggest the existence of higher chlorophyll concentrations prior to the bio-profiler deployment. This is in agreement with satellite ocean colour animations on which high biomass development is observed in December 2013 in the area of the bio-profiler deployment (see Fig. 1e and $\mathrm{f}$ and the animation "bloom 2013" in the Supplement). After this initial difference, the $b_{\mathrm{bp}}$ variations followed those of chlorophyll along the rest of the trajectory.

Bio-profiler \#3, launched in late January 2014 in the northern portion of the recirculation feature, followed a similar trajectory to that of bio-profiler \#1 launched in October 2011 and encountered much warmer waters with similar mixed layer depths, between 40 and $70 \mathrm{~m}$ (Fig. 5). Presumably this represents seasonal warming as salinities were similar to those encountered in spring $(\sim 33.85)$, and the warming from $\sim 3$ to nearly $6^{\circ} \mathrm{C}$ is consistent with seasonal warming amplitudes observed in satellite surface temperature records for unfertilised open ocean Polar Frontal Zone waters (Trull et al., 2001). Persistent high chlorophyll levels were also observed initially in the recirculation region (up to $\sim 4$ vs. $\sim 1 \mu \mathrm{g} \mathrm{L}^{-1}$ ), but the float did not cross the Gallieni Spur (GS in maps of Fig. 5), where bio-profiler \#1 encountered values up to nearly $10 \mu \mathrm{g} \mathrm{L}^{-1}$. During its transit south near $75^{\circ} \mathrm{E}$, only Polar Frontal Zone waters were encountered, and chlorophyll levels remained moderately high (between 1 and $2 \mu \mathrm{g} \mathrm{L}^{-1}$ ). At the beginning of the trajectory, the particulate backscattering $b_{\mathrm{bp}}$ signal evolved in concert with the chlorophyll signal, but with a 7-10-day delay. Another difference between the two biomass parameter evolutions was the large increase in $b_{\mathrm{bp}}$ compared to chlorophyll between the surface and $100 \mathrm{~m}$, right after the profiler turned southward in the vicinity of the Gallieni Spur ( $\sim$ profiles 190-205, end of March).

Bio-profiler \#4, deployed well east of the recirculation feature in early February, was initially in warm, quite salty, and well-oxygenated waters, characterised by moderate biomass (first 80 profiles: $T \sim 5.5^{\circ} \mathrm{C}, S \sim 33.8, \mathrm{O}_{2} \sim 310 \mu \mathrm{mol} \mathrm{kg}{ }^{-1}$, Chl $\left.a<1.5 \mu \mathrm{g} \mathrm{L}^{-1}, \log \left(b_{\mathrm{bp}}\right) \sim 3.35 \mathrm{~m}^{-1}\right)$. As its trajectory approached the Gallieni Spur, surface waters became progressively warmer, fresher, and less oxygenated (profiles 80 250: $T \sim 7^{\circ} \mathrm{C}, S \sim 33.7, \mathrm{O}_{2} \sim 290 \mu \mathrm{mol} \mathrm{kg}^{-1}$ ). During this time, the bio-profiler recorded high chlorophyll and particle concentrations (chlorophyll values reaching up to $3 \mu \mathrm{g} \mathrm{L}-1$ for profiles 80-130). This high biomass could be a remnant of the rich filament that transited in this area a month prior to the visit of the bio-profiler (see the animation "bloom 2013" in the Supplement). As the bio-profiler drifted further east, it was entrained in a relatively stationary cyclonic eddy where it performed several loops before exiting to the south (pro- 
files $\sim 130-240$, mid-March-mid-April). This eddy can be identified from altimetry as retentive - i.e. capable of entraining Lagrangian particles for, in this case, a few weeks to 1 month (d'Ovidio et al., 2013; Fig. 11b). While retained by this mesoscale eddy, the bio-profiler measured a relatively constant profile of temperature and salinity, with slowly decreasing Chl $a$ concentrations and $b_{\text {bp }}$ (Fig. 11). Relatively constant hydrological properties throughout this period and the repeated looping suggest a largely Lagrangian trajectory within a single water parcel at this time. Of all the observations, this region displayed surface waters with the highest temperatures and lowest salinities $\left(T \sim 8.0^{\circ} \mathrm{C}, S \sim 33.6\right)$.

\section{Discussion}

With this overview of the spatial and temporal characteristics of our observations in hand, we proceed to evaluate our research questions.

\subsection{Do the satellite images of surface chlorophyll reflect water column contents?}

As discussed in the Introduction, it is important to determine whether the water column information provided by the bio-profilers changes perspectives on the mesoscale distributions of chlorophyll as seen in satellite images (Fig. 1). This is a larger issue than whether our in situ measurements of surface values differ from satellite values. We did not evaluate that question owing to extensive cloud cover greatly limiting match-ups between bio-profiler and satellite observations, and because we know that both our sensor calibrations and the satellite algorithms have large uncertainties (see Sects. 2.2 and 2.3). Instead, we examined the bio-profiler water column observations to determine what biases might be expected from observing only their upper portions, i.e. as a satellite would. There are two aspects of this issue that we could readily address: (1) were subsurface chlorophyll maxima commonly present below the depth of satellite observation, and did they vary spatially or temporally? (2) Were surface chlorophyll values linearly and tightly correlated with water column inventories with similar dynamic ranges, or were surface values poor guides to water column inventories? We address these issues in this order in the following paragraphs.

Our statistics on the occurrence of subsurface chlorophyll maxima (Table 3) show that these features were present in a significant fraction of the profiles (up to $14 \%$ of the night profiles and up to $21 \%$ of the quenching-corrected day profiles). They mostly occurred at depths greater than the MLD (Table 3) and were thus too deep to be taken into account in the satellite observations. Without radiation sensors on the bio-profilers, the first penetration depth $\left(z_{\text {pd }}\right.$, optical depth at which the downwelling irradiance falls to $1 / e$ ) that characterises satellite observations could not be directly estimated, but based on the model of Morel and Maritorena (2001, their Fig. 6), and using the relationship $z_{\mathrm{pd}}=z_{\mathrm{eu}} / 4.6$ for the euphotic zone definition of the $1 \%$ photosynthetically active radiation level (Gordon and McCluney, 1975), it was at most $10-15 \mathrm{~m}$, and thus always within the mixed layer. Thus, we focused on these subsurface maxima occurring below the MLD (hereafter SubMax $>$ MLD) and we examined the location of the profiles exhibiting these features as well as their associated depth (see Fig. 7a, b, d, and e).

These SubMax $>$ MLD were quite localised. They occurred primarily near the plateau or close to the location of the Polar Front. Specifically, most of the profiles exhibiting this feature were found in the vicinity of the steep slope between the northern Kerguelen Plateau and the Gallieni Spur, between 40 and $80 \mathrm{~m}$ depth (Fig. 7a, b, d, and e). Occurrences of SubMax $_{>M L D}$ were much more sporadic south of $50^{\circ} \mathrm{S}$, on the south-eastward trajectories of bio-profilers $\# 1$ and \#2. These conclusions about the locations of subsurface chlorophyll maxima are similar for both night and day occurrences (stars and open circles in Fig. 7, respectively), although $\operatorname{SubMax}_{>}$MLD of day-flagged profiles occurred mostly at shallow depths $(<50 \mathrm{~m}$, Fig. $7 \mathrm{~b}$ and d) and may result from an under-correction of the surface-quenched Chl $a$ concentrations (see Sect. 2.2). It seems that light limitation may not be a major driver of subsurface Chl $a$ maxima via the mechanism of increased Chl $a$ production per cell, at least under a certain threshold of Chl $a$ content, since SubMax $>$ MLD observed by bio-profilers \#3 and \#4 occurred more frequently when the mixed layer was deep (for $2.5 \mu \mathrm{g} \mathrm{L}{ }^{-1} \leq$ Chl $a \leq 5 \mu \mathrm{g} \mathrm{L}{ }^{-1}$; Fig. 7c and f). However, the quasi-ubiquitous concomitance of $\mathrm{SubMax}_{>}$MLD for bioprofiler \#1 with shallow mixed layers, less than $50 \mathrm{~m}$, suggests that, above a certain threshold of Chl $a$ content, selfshading may promote pigment production by phytoplankton at depth.

Subsurface chlorophyll maxima beyond the reach of satellite imagery can be thought of as a specific class of the wide range of possible chlorophyll distributions (such as varying thicknesses of relatively constant near-surface biomass layers, or changes in the rate of decrease in biomass with depth) that could introduce bias between surface concentration and water column inventory perspectives. To gain perspective on the overall importance of these possibilities, we compared surface chlorophyll concentrations measured by the profilers (using the shallowest $\sim 10 \mathrm{~m}$ depth observation since this was reliably within both the $1 / e$ satellite ocean colour penetration depth and the mixed layer) with their column inventories calculated from all observations in the top $200 \mathrm{~m}$ (since chlorophyll distributions generally reduced to background values below this depth). These comparisons, shown in Fig. 8a (left column), display reasonably linear relationships over almost the entire range of both night- and daytime observations. This was especially true for bio-profilers $\# 1$ and \#3 (correlation coefficients $r^{2}=[0.60-0.85]$ ), which include high chlorophyll values (greater than $2 \mathrm{mg} \mathrm{m}^{-3}$ for 
the surface concentration and greater than $160 \mathrm{mg} \mathrm{m}^{-2}$ for the $0-200 \mathrm{~m}$ inventory). Most of the flagged daytime profiles (red circles in Fig. 8a) seem to be shifted slightly left of the linear regression lines, suggesting that they may well represent under-corrected quenched chlorophyll rather than true features. Overall, qualitatively, these quite linear relationships between surface $\mathrm{Chl} a$ concentration and 0-200 m integrated $\mathrm{Chl} a$ content suggest that satellite observations are reasonably good indicators of the spatial distributions of the water column chlorophyll inventories.

Concerning the particulate backscattering signal, the linear correlations between surface values and inventories were generally not as strong as for $\mathrm{Chl} a$, except for bio-profiler $\# 3$, as shown in Fig. 8b (right column: $\mathrm{r}^{2}=[0.29-0.74]$ ). It appears that surface $b_{\mathrm{bp}}$ values lower than $\sim 2 \times 10^{-3} \mathrm{~m}^{-1}$ vary similarly to the $0-200 \mathrm{~m} b_{\text {bp }}$ inventories, whereas higher surface values exhibit noisier correlations when compared to the 0-200 m integrated $b_{\mathrm{bp}}$ contents (see the slope breaks in the relationship between the surface and 0-200 m integrated $b_{\mathrm{bp}}$ in Fig. 8b). The origin of this non-linearity is not clear, and its evaluation is potentially compromised by the spikiness of the $b_{\mathrm{bp}}$ records and their poor vertical resolution. The particulate backscatter profiles (Figs. 2b, 3e, 4e, 5e, 6e, and 12e) suggest that spikes may be particularly common at the base of the mixed layer and below, and thus might reflect differential control of phytoplankton and total particle populations. Future deployments with improved firmware to yield higher resolution may be able to advance the interesting possibility that backscatter information can provide ecosystem perspectives beyond phytoplankton biomass alone.

Because our qualitative assessment indicated that surface Chl $a$ concentrations provide a relatively unbiased indication of the water column Chl $a$ inventory, we now try to go a little bit further towards a quantitative assessment of possible biases between satellite and in situ Chl $a$ perspectives. First, we compared the coefficients of variation (i.e. the ratio of the standard deviation to the mean) of the surface chlorophyll concentrations and of the water column inventories. When only the night data were used, so as to avoid quenching correction uncertainties, surface distribution coefficients of variation (\#1: 82; \#2: 20; \#3: 39; \#4: $43 \%$ ) revealed very similar relative dispersions to the water column $(0-200 \mathrm{~m})$ inventory coefficients of variation (\#1: 84; \#2: 20 ; \#3: 34; \#4: $31 \%$ ). Thus, satellite images reasonably reflect the relative range of mesoscale variability in water column phytoplankton biomass accumulations. Surprisingly, surface chlorophyll values (i.e. satellite images) would tend to slightly overestimate the relative dispersion of $\mathrm{Chl} a$ data for bio-profilers \#3 and \#4, despite those profiles exhibiting the largest numbers of night subsurface maxima (in \%, Table 3 ). This means that the association of high surface chlorophyll concentrations with shallow chlorophyll layers was more important than the presence of subsurface chlorophyll maxima in determining the relationships between surface and water column inventories.
To further explore this issue, we calculated expected water column inventories for chlorophyll layers confined to the physical mixed layer depths at the time of observation (by multiplying each surface concentration by its associated mixed layer depth, MLD). This is akin to trying to improve satellite assessments using mixed layer depth information from, for example, standard ARGO floats that measure only temperature and salinity. These comparisons are shown in Fig. 9a and reveal that this approach badly underestimates water column inventories (at least with our MLD definition) and that this underestimation is very common. Most of the "0-200 m integrated Chl $a$ / (surface Chl $a \times$ MLD)" ratios range from $1 / 1$ to $4 / 1$, with a few profiles of bio-profilers $\# 1$ and \#3, at the time when they recorded the highest biooptical values, reaching ratios of $20 / 1$ (profiles $\sim 70-130$ for bio-profiler \#1 and profiles $\sim 0-70$ for bio-profiler \#3). Moreover, the colour coding in Fig. 9a shows that this bias is strongest for shallow mixed layers in general. In other words, the presence of significant amounts of chlorophyll below the mixed layer is very common (though generally not as local vertical chlorophyll maxima, for which our statistics confine the occurrence of those exceeding $60 \%$ of surface to $17 \%$ of the sampled locations and those exceeding $100 \%$ of surface to $11 \%$ of the sampled locations). Notably, this bias still persists strongly if we change our MLD definition to the much larger criterion of Levitus (1982; density increase of $0.125 \mathrm{~kg} \mathrm{~m}^{-3}$ relative to the density at $0 \mathrm{~m}$ ). For this criterion, the (surface Chl $a \times$ MLD) estimation ranged between half and twice the $0-200 \mathrm{~m}$ integrated Chl $a$ content for MLD deeper than $60 \mathrm{~m}$ (close to half for MLD $\sim(60-$ 90) $\mathrm{m}$ and surface $\mathrm{Chl} a<2 \mu \mathrm{g} \mathrm{L}^{-1}$ to close to twice for MLD $>120 \mathrm{~m}$ and surface Chl $a>2 \mu \mathrm{g} \mathrm{L}^{-1}$ ). However, (surface Chl $a \times$ MLD) estimations were still two to four times lower than the $0-200 \mathrm{~m}$ integrated $\mathrm{Chl} a$ content recorded by the bio-profilers when the MLD ranges between 40 and $60 \mathrm{~m}$ (not shown).

The most probable explanation for these observations is that the mixed layer at the time of observation was shallower than at the time of generation of the biomass. This is of course expected as a result of seasonal shallowing of the mixed layer, but the magnitude of the effect is important to recognise (as we have shown above), as it is well above what could be corrected using some other mixed layer depth criterion. Interestingly, there appears to be a relatively simple hyperbolic relationship between the ratio " $0-200 \mathrm{~m}$ integrated Chl $a$ " / "surface Chl $a \times$ MLD" (hereafter designated as X) and MLD, as shown in Fig. 9b for the MLD definition of Park et al. (1998). It also holds for the MLD definition of Levitus (1982). This $X$ vs. MLD hyperbola reaches an asymptote of $X \sim 1$ for MLD values close to the 150-200 m depths of regional winter mixed layers (visible as temperature minima remnant signatures of winter cooling in profiles south of the Polar Front in Figs. 3b, 4b, 5b, and 6b). Moreover, the curve is reasonably well parameterised by $X \sim \mathrm{MLD}^{t} / \mathrm{MLD}^{w}$, in which the superscripts $t$ and $w$ indicate mixed layer depths 

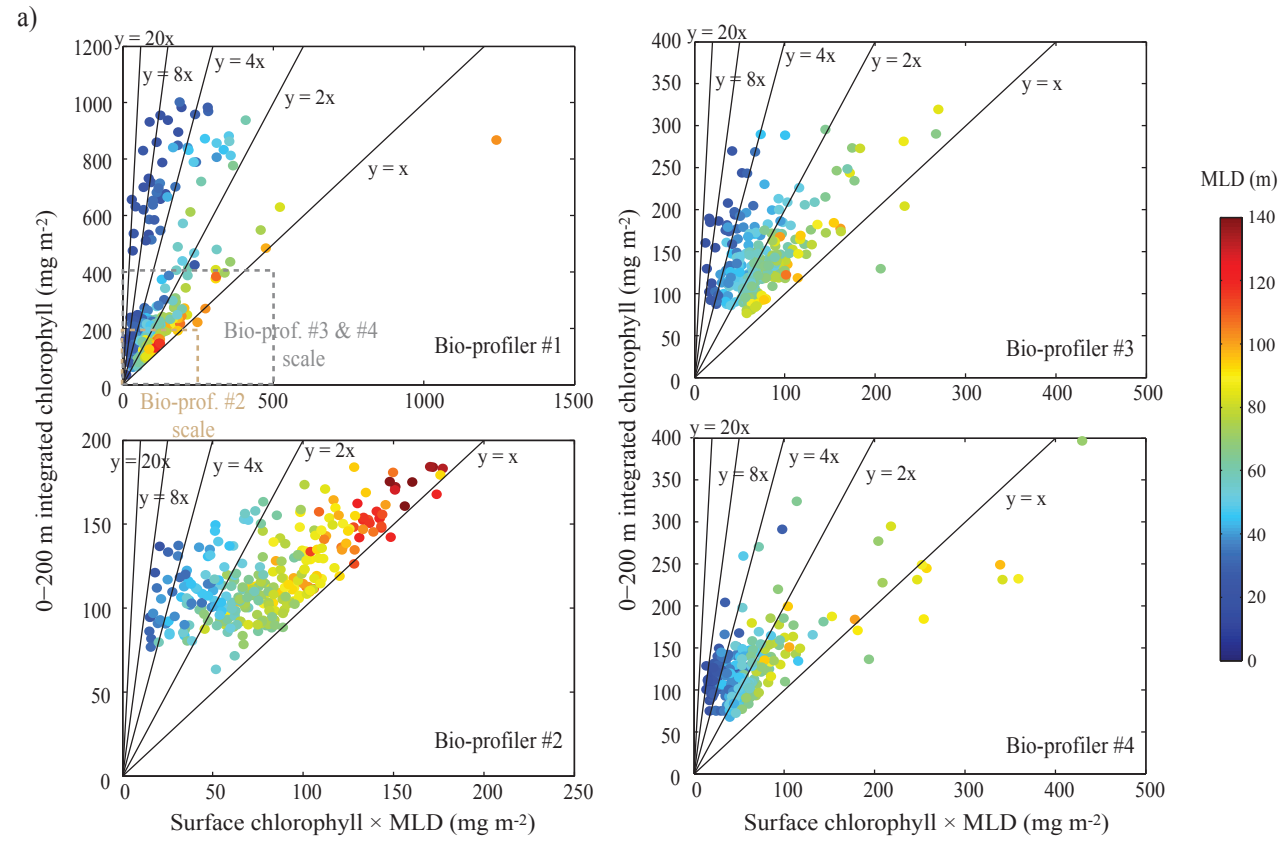

b)

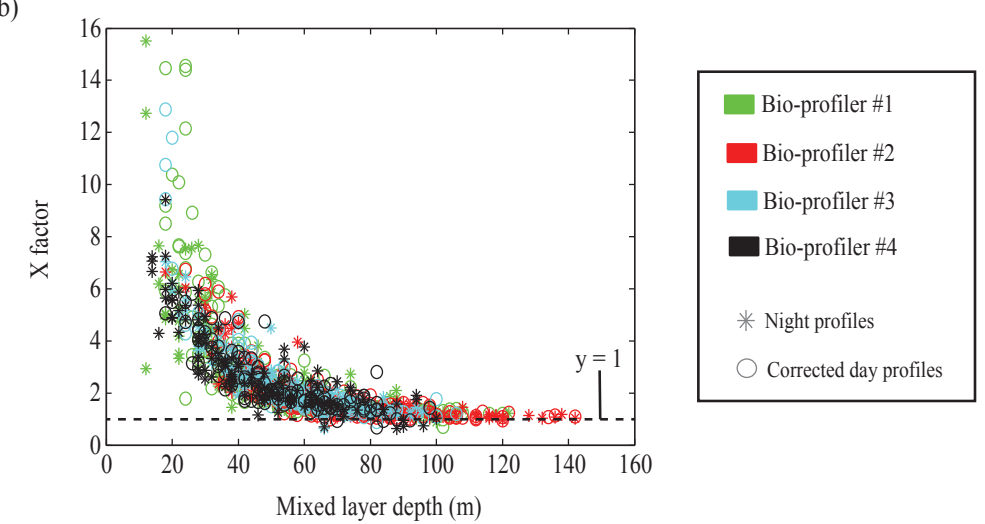

Figure 9. (a) Chlorophyll water column inventories (in $\mathrm{mg} \mathrm{m}^{-2}$ ), estimated by multiplying surface chlorophyll concentrations by the mixed layer depth, compared to chlorophyll inventories $\left(0-200 \mathrm{~m}\right.$; in $\left.\mathrm{mg} \mathrm{m}^{-2}\right)$ recorded by the bio-profilers. Only night and unflagged day profiles are represented. The colour code shows the associated depth of the mixed layer (in m). The five lines $y=x, y=2 x, y=4 x, y=8 x$, and $y=20 x$ are given as indicators to quantify the ratio between the "surface Chl $a \times$ MLD" product and the 0-200 m integrated Chl $a$. (b) Representation of the $X$ factor ( $X=(0-200 \mathrm{~m}$ integrated Chl $a) /($ surface Chl $a \times \mathrm{MLD})$ ) as a function of the mixed layer depth (in m), for the total data set. Symbols and colours are defined in the legend.

at the time of observation and the end of winter, respectively. This relationship could arise if most biomass accumulation occurred in early deep mixed layers with subsequent stratification adding little additional biomass, or if mixed layers shallowed and deepened episodically as biomass accumulation developed throughout the season.

Overall, these results emphasise the major challenges that are present for connecting surface chlorophyll distributions to total water column biomass and primary productivity, since they reveal that physical mixed layer depths are often not a reliable guide to biomass distributions. These physical and biological responses seem to be modulated differently on diel, weather, and seasonal timescales, and are also affected by the mesoscale and sub-mesoscale interleaving of water parcels. The quantification of near-surface mixing (i.e. going beyond the limited mixed layer depth concept) is currently under very active exploration and debate in the context of seasonal drivers of production (Behrenfeld, 2010; Taylor and Ferrari, 2011), and these data reveal the need to extend those perspectives to shorter time and space scales. The presence of significant amounts of chlorophyll below the mixed layer is also important to its ultimate fate - if this biomass is not re-entrained then it may well contribute preferentially to ex- 
port and to mesopelagic oxygen consumption (issues which we revisit in Sect. 4.3 below).

\subsection{Do regions of high biomass correlate with (local) oceanographic properties?}

To evaluate this issue, we examined bivariate regressions of Chl $a$ inventories ( $0-200 \mathrm{~m}$ ) with physical water column characteristics, after having separated the observations into two groups: (1) Chl $a$ inventories $>200 \mathrm{mg} \mathrm{m}^{-2}$ in biomassrich regions close to the plateau, and (2) Chl $a$ inventories $\leq 200 \mathrm{mg} \mathrm{m}^{-2}$ in moderate-biomass regions far from the plateau (the high- and moderate-biomass regions considered here are identified by red and yellow rectangles in Figs. 3c, 4c, 5c, and 6c). As shown in Fig. 10 (a, b, and c), the regions richest in biomass encountered by bio-profiler \#1 in 2011 and bio-profiler \#3 in 2014 were associated with waters with very similar properties, specifically moderate temperatures $\left(3.5-5{ }^{\circ} \mathrm{C}\right)$, high salinities (33.82-33.85), and thus relatively high densities (sigma values of $26.7-26.9 \mathrm{~kg} \mathrm{~m}^{-3}$ ). The bioprofiler \#1 distributions of chlorophyll with these properties showed linear decreases on either side of these values, suggestive of mixing with surrounding waters much poorer in $\mathrm{Chl} a$. This characteristic is also observed between integrated Chl $a$ and mean surface oxygen saturation $\left(\mathrm{O}_{2}\right.$ sat , Fig. 10f), for which the high $\mathrm{O}_{2 \text { sat }}$ states (reaching $10 \%$ supersaturation) indicate oxygen production in these high-biomass waters (since these values exceed expectations from processes such as warming or bubble injection; Shadwick et al., 2014). Relatively high biomass was also encountered in waters with extreme $T-S$ properties (the warmest and freshest observed) in the vicinity of the Gallieni Spur by bio-profiler \#4 (black symbols in Fig. 10). Thus, there was no unique class of waters with high biomass. This perspective is further reinforced by the lack of any clear relationships between chlorophyll inventories and local water column properties for regions of moderate biomass, including vs. mixed layer depth and the intensity of stratification as represented by the Brunt-Väisälä frequency (Fig. 10, right column). These low-biomass waters also exhibited lower $\mathrm{O}_{2}$ sat states (95-103\%) than those of biomass-rich areas. The under-saturated oxygen levels reflect either strong local respiration or the supply of low-oxygen waters from below, with these processes difficult to distinguish (except for specific portions of the bio-profiler \#4 trajectory, where time series within constant physical property layers were obtained, as discussed in Sect. 4.3).

Linking local water parcel properties to past water trajectories with respect to the Kerguelen Plateau, as a known natural source of iron fertilisation, provides an additional view of the role of water mass properties in the control of chlorophyll inventories. For the waters richest in Chl $a$ $\left(T \sim 4{ }^{\circ} \mathrm{C}, S \sim 33.83, \sigma \sim 26.8 \mathrm{~kg} \mathrm{~m}^{-3}\right.$ ) encountered by bioprofiler \#1, surface drifters released during the KEOPS2 voyage (d'Ovidio et al., 2015) suggest these waters derive from the northern Kerguelen Plateau. The computation of trajec- tories based on satellite altimetry (see Sect. 2.3) for all the bio-profilers confirms this perspective and also indicates that the time since a water parcel left the plateau (Fig. 11b) is another important determinant of chlorophyll levels (presumably as a result loss of $\mathrm{Fe}$ over time after its addition from the plateau; d'Ovidio et al., 2015). These results are shown in Fig. 11. Fig. $11 \mathrm{~b}$ and d compares water age and origin with the 0-200 $\mathrm{m} \mathrm{Chl} a$ inventories for spring (bio-profiler $\# 1$, in blue in the plots) and summer (bio-profilers \#2, \#3, and \#4, in black in the plots). Besides a strong seasonal difference - spring values range up to $1000 \mathrm{mg} \mathrm{m}^{-2}$, whereas in the summer few measurements exceed $300 \mathrm{mg} \mathrm{m}^{-2}$ - water parcels corresponding to high $\mathrm{Chl} a$ inventories appear to be waters that have recently left the Kerguelen Plateau (2040 days of water age; Fig. 11a) and come generally from its northern part $\left(47^{\circ} \mathrm{S}\right.$ to $49^{\circ} \mathrm{S}$; Fig. 11c). Bio-profilers locations that correspond to water parcels that have not touched the plateau in the last 100 days (points shown in white for water age $=100$ in Fig. 11b) do not present any high integrated $\mathrm{Chl} a$ values, suggesting that the main source of iron fertilisation for the explored water masses is horizontal advection from the Kerguelen Plateau. This correlation of high Chl $a$ inventories with age since leaving the plateau is unlikely to be biased by the lower frequency of sampling (shown in the Fig. $11 \mathrm{~b}$ inset) of older waters, given that a statistical bootstrap test based on a $10^{4}$ sampling of a uniform distribution of integrated Chl $a$ at the sampling frequency of each water age yielded a probability $(p)$ of not-sampling-integrated Chl $a$ values greater than $200 \mathrm{mg} \mathrm{m}^{-2}$ for water parcels with water ages greater than 40 days of $p<10^{-4}$.

These results suggest that the northern Kerguelen Plateau is an important target region for future studies of iron delivery mechanisms into the plume downstream. In terms of the secondary influences of mixed layer depth and stratification, the bio-profiler \#1 profiles with integrated Chl $a$ greater than $600 \mathrm{mg} \mathrm{m}^{-2}$ were mainly characterised by a shallow mixed layer, lower than $60 \mathrm{~m}$ (Fig. 10d), and a low stratification $\left(-0.01 \mathrm{~s}^{-2}<\max N^{2}<0 \mathrm{~s}^{-2}\right.$; Fig. 10e). Below this Chl $a$ inventory threshold, no clear relationships emerged between MLD or $N^{2}$ and 0-200 m integrated chlorophyll (Fig. 10d and e). From a steady-state perspective, this lack of correlation could arise because mixed layers were shallow enough that light limitation was not sufficient to halt phytoplankton accumulation, yet not so shallow that mean mixed layer light levels allowed light-promoted growth to reach accumulations that became self-shading (viewpoints that have been developed previously, based on relationships between fluorescence and mixed layer depth observations in this region using sensors on elephant seals; Blain et al., 2013). Importantly, our observations emphasise that chlorophyll distributions do not track the shoaling of mixed layer depth on seasonal or weather timescales, and thus that MLD variability is unlikely to show simple relationships to biomass accumulation. This point has also been emphasised in terms of competing effects of light and Fe limitation responses to MLD 

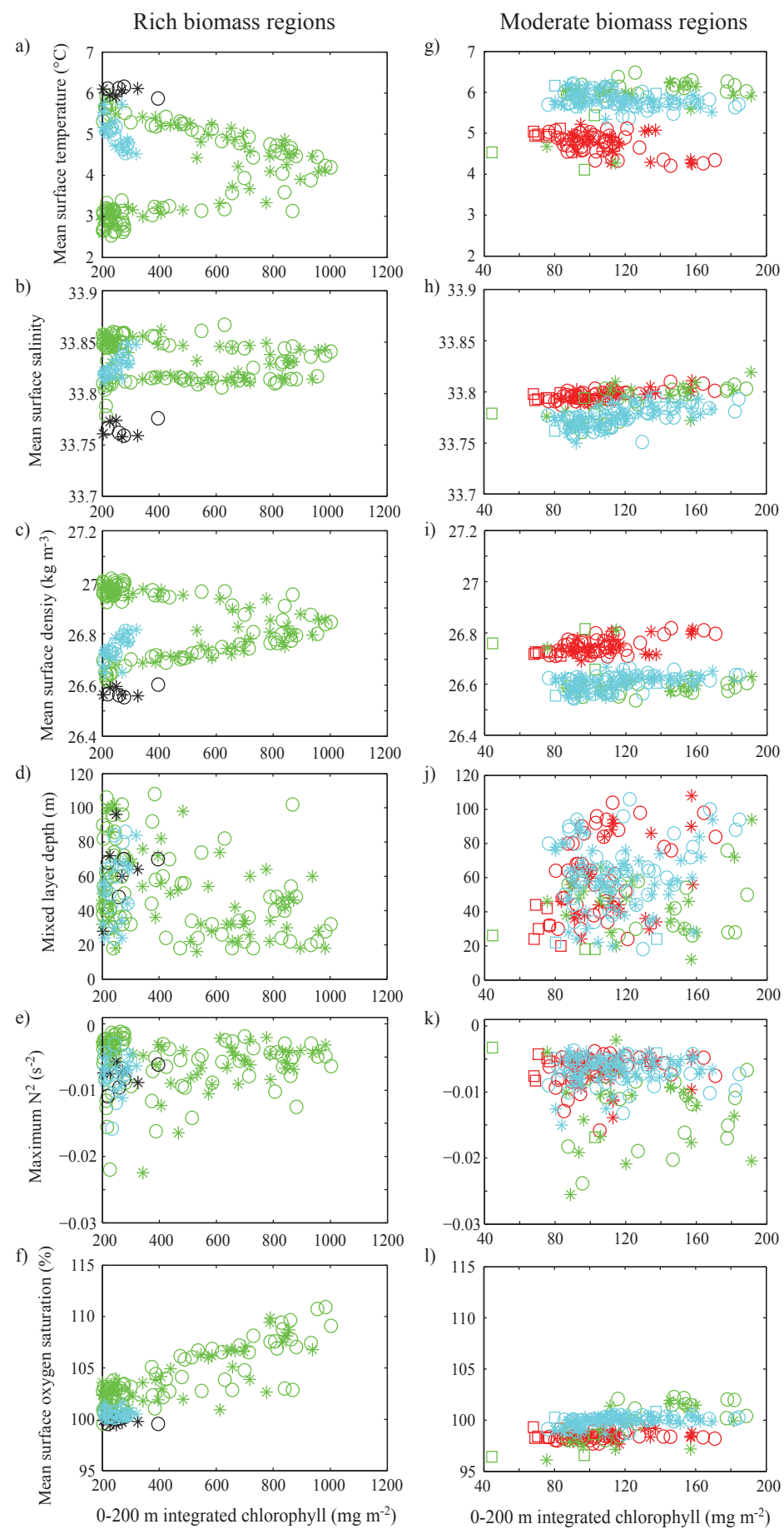

\begin{tabular}{|lc|}
\hline Bio-profiler \#1 $\quad$ Bio-profiler \#2 & Bio-profiler \#3 \\
* Night profiles & $\begin{array}{l}\text { Corrected day profiles which still exibit, } \\
\text { in the surface layer, a large concentration } \\
\text { decrease toward low surface values }\end{array}$ \\
\hline
\end{tabular}

Figure 10. Relationship between $0-200 \mathrm{~m}$ integrated chlorophyll $a$ concentration and various water properties for (a-f) high-biomass regions close to the plateau (bio-profilers \#1 and \#3) or entrapped in eddies (bio-profilers \#2 and \#4; red rectangles in Figs. 3, 4, 5, and 6) and (g-l) moderate-biomass regions far from the plateau (yellow rectangles in Figs. 3, 4, 5 and 6). (a, g) Surface temperature (in ${ }^{\circ} \mathrm{C}$ ), (b, h) surface salinity (unitless), (c, i) surface density (in $\left.\mathrm{kg} \mathrm{m}^{-3}\right),(\mathbf{d}, \mathbf{j})$ mixed layer depth (MLD; in m), (e, $\left.\mathbf{k}\right)$ maximum Brunt-Väisälä frequency squared $\left(N^{2}\right.$; in s $\left.{ }^{-2}\right)$, and $(\mathbf{f}, \mathbf{l})$ oxygen saturation state (in \%). Symbols and colours are defined in the legend. 
a)

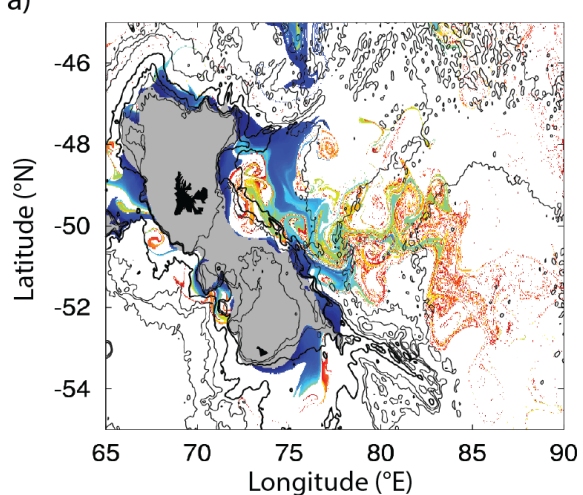

c)

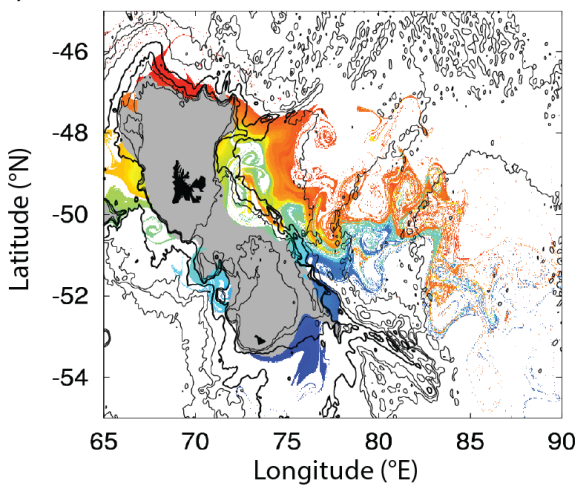

Age (days)

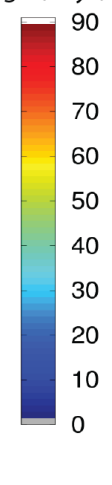

Origin $\left({ }^{\circ} \mathrm{N}\right)$

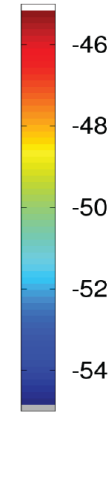

b)

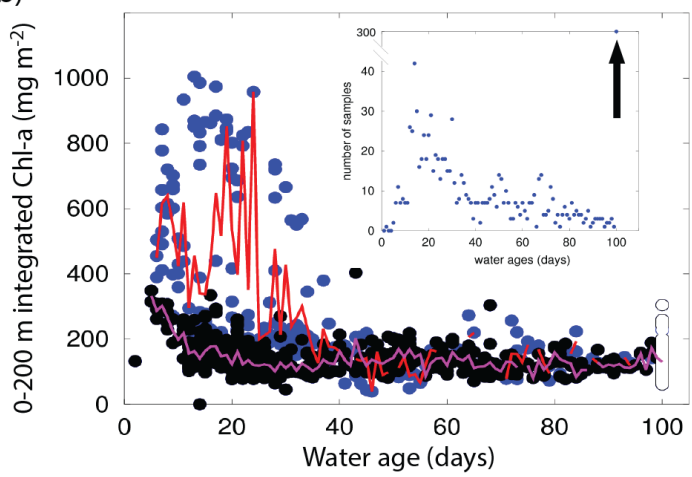

d)

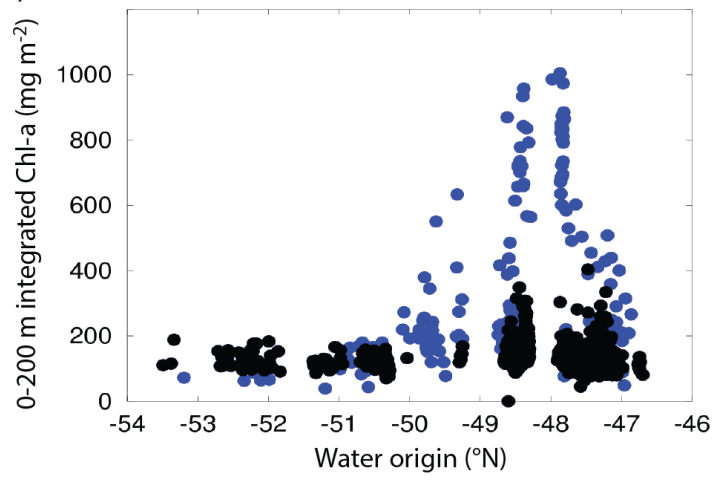

Figure 11. Lagrangian diagnostics computed from altimetry. Maps of age and origins of the water parcels shown in plots (a) and (c) are from Fig. 4 of d'Ovidio et al. (2015). White pixels represent water parcels that have not touched in the past 100 days the Kerguelen Plateau (defined by the $700 \mathrm{~m}$ isobath and shown in grey). Comparison of these age and origin metrics with the bio-profiler total integrated Chlorophyll $a$ values are shown in plots (b) and (d). Blue dots correspond to data collected during spring (bio-profiler \#1; mean values in red) and black dots to data collected during summer (bio-profilers \#2, \#3, and \#4; mean values in magenta). White dots correspond to water parcels that have not touched the Kerguelen Plateau. The inset in plot (b) shows the number of measurements for each water age. The black arrow highlights the fact that low Chl $a$ levels associated with water parcels that have not touched the Kerguelen Plateau within the last 100 days are supported by a large number of samples and, thus, seem to be a robust feature.

variability (Joubert et al., 2014), for waters where vertical Fe supply is dominant (rather than the horizontal dominance of supply studied here).

\subsection{Can the fate of surface enrichments in biomass be determined, and if so, what is the percentage of biological production exported?}

Evaluating this question requires the extraction of a temporal perspective from the bio-profiler records, and is thus only possible for portions of their trajectories which appear to be essentially Lagrangian. The best record for this approach is for bio-profiler \#4 during the period when it carried out several clockwise loops in late autumn, i.e. for profiles 150-240 (Fig. 6a). During this time, its trajectory was very similar to that expected based on surface currents estimated from satellite altimetry, the density stratification of the water column was relatively steady, and the $T-S$ profiles were tightly grouped (Fig. 12b, c and d). These observations suggest that the profiler remained within a single water parcel that was entrained by a retentive eddy and underwent only small exchanges with surrounding waters, as shown by slightly warmer (profiles 165-170 and 200-220) and cooler (profiles 175-195) conditions along the trajectory (these are discussed further below).

At the start of this period (blue lines subset in Fig. 12e), chlorophyll profiles showed moderate to high surface and subsurface layer levels, well above HNLC background values, with some profiles exhibiting subsurface maxima reaching up to $1.5 \mu \mathrm{g} \mathrm{L}^{-1}$ between 50 and $70 \mathrm{~m}$ depth and up to $1 \mu \mathrm{g} \mathrm{L}^{-1}$ around $120 \mathrm{~m}$ depth. Both the surface constant Chl $a$ layer and the subsurface "chlorocline" layer (by analogy to thermocline or halocline, "chlorocline" is defined here as the depth range with the highest chlorophyll concentration gradient) were thick, equal to $\sim 80$ and $\sim 50 \mathrm{~m}$, respectively. The origin of the smaller and variable subsurface maxima seen in some profiles in Fig. 12e is uncertain. One possibility is that they are remnants of the high surface chlorophyll biomass observed just prior to the eddy entrapment (visible 

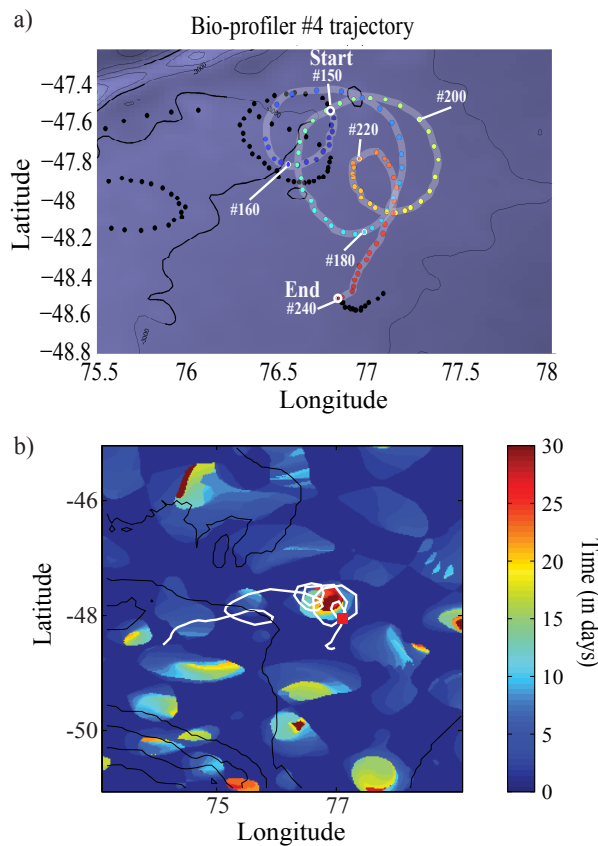

c)

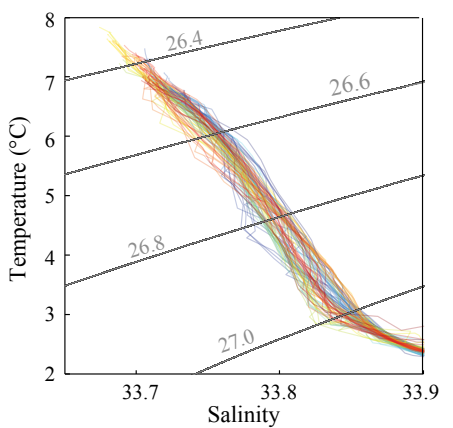

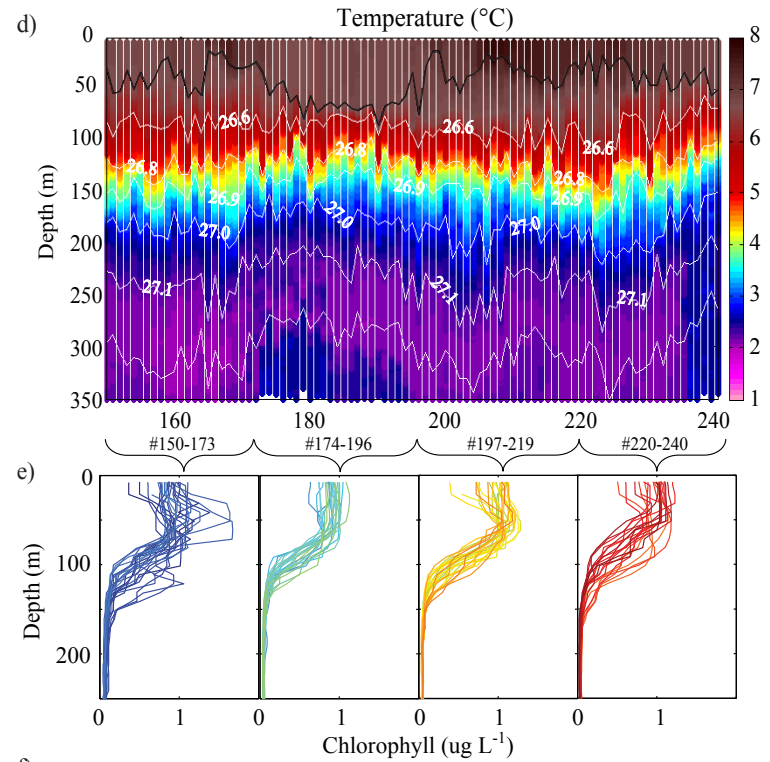
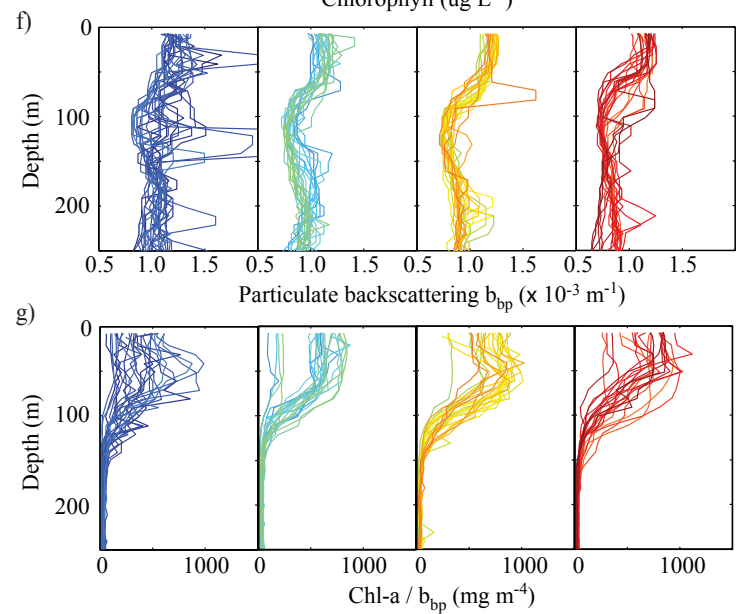

Figure 12. Eddy entrapment of bio-profiler \#4. (a) Identification of entrapment along the bio-profiler trajectory, with the colour of the points changing, from blue to red over time, from profile 150 to profile 240. (b) Overlay of bio-profiler trajectory (white line) and eddy retention indices, showing the portion of the trajectory within a long-lasting (more than 30 days) retentive structure. The red square marks the temporal reference (profile 177) from which the Lagrangian trajectories were computed for the retention statistic, as described in Sect. 2.3. (c) Temperature-salinity diagram. Colours correspond to locations on the map in (a). (d) Temperature vs. depth section with mixed layer depth (black line) and isopycnals indicated (white lines). (e) Chlorophyll profiles, coloured as on the map and separated, for the sake of clarity, in four subsets of $\sim 23$ profiles (equivalent to $\sim 2$ weeks of data acquisition). (f) As (e) but for particulate backscattering ( $b_{\mathrm{bp}}$ ) profiles. (g) As (e) but for the chlorophyll $/ b_{\mathrm{bp}}$ ratio. Note that chlorophyll and $b_{\mathrm{bp}}$ signals were filtered for visual clarity using a three-point running median.

in Fig. 6c and the "bloom 2013" animation in the Supplement) that had been carried to depth by particle settling or by subduction of the denser, saltier, and slightly cooler water associated with that high biomass. Associated $b_{\mathrm{bp}}$ profiles showed similar large variations with strong local maxima correlated to local Chl $a$ maxima (blue lines subset in Fig. 12f). The strong variability in the $\mathrm{Chl} a / b_{\text {bp }}$ profiles over the first $100 \mathrm{~m}$ suggests possible changes in the composition of the particulate assemblage (blue lines subset in Fig. 12g).
During the Lagrangian eddy entrapment period, the surface mixed layer chlorophyll levels declined further from 1.5 to $\sim 1 \mu \mathrm{g} \mathrm{L}^{-1}$ (Figs. 6c and 12e). Since the constant chlorophyll surface layer shallowed progressively with time, this Chl $a$ decrease did not result from the possible effect of dilution by mixed layer deepening (i.e. entrainment). Furthermore, the chlorocline content decreased briefly before reincreasing progressively in its upper part, and then its deeper part. In parallel, $b_{\mathrm{bp}}$ and $\mathrm{Chl} a / b_{\mathrm{bp}}$ profiles became tighter and tighter (light blue to orange profiles in Fig. 12f and g) 

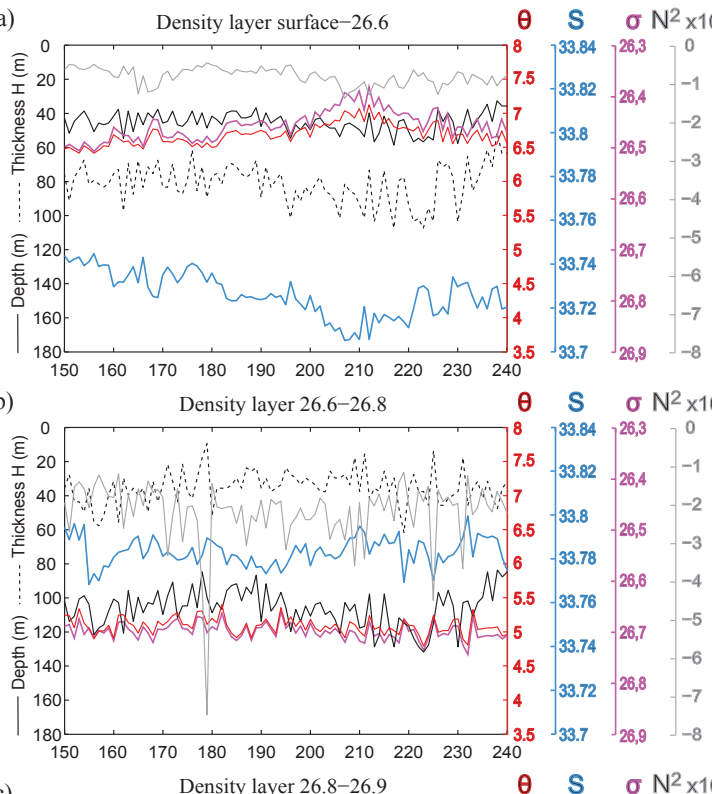

$\mathrm{S} \sigma \mathrm{N}^{2} \times 10^{3}$

$733.84-26,3 \quad 70$
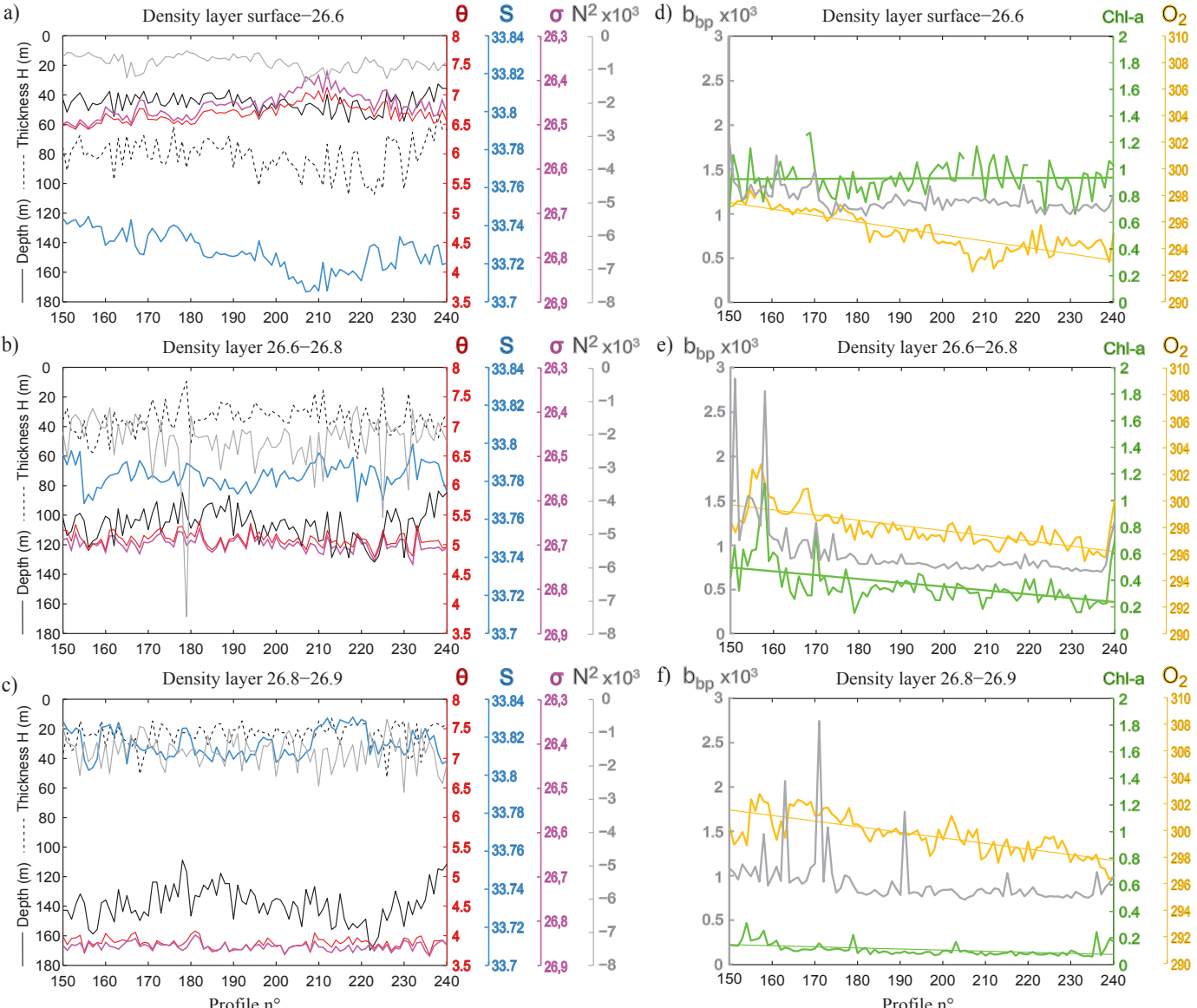

$\sigma \mathrm{N}^{2} \times 10^{3}$

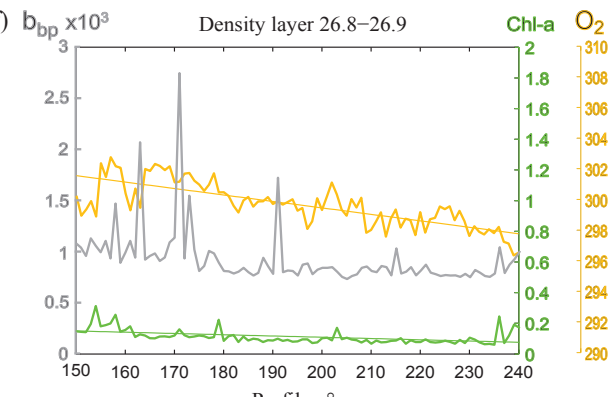

Figure 13. Temporal evolution of physical and biological properties during the eddy entrapment of bio-profiler \#4 for three density layers, with sigma ranges of surface to 26.6, 26.6-26.8, and 26.8-26.9. Left column plots (a-c) show physical properties: mean depth (in m, black line and scale), thickness (in $\mathrm{m}$, dashed black line and black scale), temperature $\left(\theta\right.$, in ${ }^{\circ} \mathrm{C}$; red line and scale), salinity ( $S$, unitless; blue line and scale), density ( $\sigma$, in $\mathrm{kg} \mathrm{m}^{-3}$; purple line and scale), and Brunt-Väisälä frequency squared $\left(N^{2}\right.$, in s ${ }^{-2}$; grey line and scale). Right column plots (d-f) show biogeochemical properties: mean chlorophyll ( $\mathrm{Chl} a$, in $\mu \mathrm{g} \mathrm{L}^{-1}$; green line and scale), particulate backscattering $\left(b_{\mathrm{bp}}\right.$, in $\mathrm{m}^{-1}$; grey line and scale), and oxygen concentrations $\left(\mathrm{O}_{2}\right.$, in $\mu \mathrm{mol} \mathrm{kg}{ }^{-1}$; orange line and scale).

before re-exhibiting larger variations (red profiles). These results suggest the possibility of some chlorophyll conversion to non-fluorescent material, or its removal by export to depth or by local respiration or both, throughout the eddy entrapment. They may also of course partly reflect small spatial variations in the structure of the biomass distributions.

To evaluate these possibilities we examined changes in three layers: the surface layer (labelled layer 1 and defined as the surface down to the 26.6 isopycnal surface) and two density layers immediately below it (layers 2 and 3, respectively, for density ranges 26.6-26.8 and 26.8-26.9). In order to characterise the existence of vertical or horizontal mixing during the eddy entrapment, mean temperature, salinity, and depth of the density layers, as well as their thickness and stratification state, are shown in Fig. 13a, b, and c). The thickness and mean depth of the surface density layer were relatively constant in the first half of the eddy entrapment, then slightly increased as some warmer and fresher - thus lighter
- water entered into the eddy structure (profiles 200-220). Contrastingly, the physical properties of the two deeper underlying density layers showed insignificant temporal trends and smaller variability over the period of interest, and thus changes in their biogeochemical properties can be attributed to local processes rather than exchanges.

The evolution of chlorophyll, particulate backscattering, and dissolved oxygen inventories also exhibited different trends and variability for each layer (as shown in Fig. 13d, $\mathrm{e}$, and f). In the surface layer (layer 1), mean chlorophyll and $b_{\mathrm{bp}}$ showed no overall temporal trend (green and grey curves in Fig. 13d, respectively), although characterised by two maxima - one at the beginning of the eddy and one coinciding with the fresher warmer water occurrence described above. The oxygen content continuously decreased steadily until after profile 200, when larger variations were observed, with a minimum content coinciding with the fresher warmer waters. Within the underlying layer (layer 2), chlorophyll, 
$b_{\text {bp }}$, and oxygen inventories showed similar evolutions: all had maximums at the beginning of the eddy and then decreased with time until the bio-profiler exited the eddy (Fig. 13e). These characteristics were also present in the deepest layer (layer 3), although with significant differences in the magnitudes of change; specifically, the oxygen decrease was similar to that of layer 2, but the chlorophyll level and its absolute magnitude of decrease were much smaller, and the $b_{\text {bp }}$ levels remained relatively high for a longer portion of the record.

To verify that these changes were oceanographic, we again evaluated fluorometer and oxygen sensor drifts, but this time only over the range of profiles considered for the eddy entrapment investigation (following the approach used in Table 2 of examining the evolution of the mean values within the depth layer 950-1000 m). Chl $a$ and $\mathrm{O}_{2}$ drifts were respectively estimated to be $+0.017 \mu \mathrm{g} \mathrm{L}-1$ and $+1.05 \mu \mathrm{mol} \mathrm{kg}^{-1}$. Thus, the temporal drifts probably lead to underestimations of the observed decrease in Chl $a$ (of $\sim 7 \%$ in layer 2 and of $\sim 20 \%$ in layer 3$)$ and of $\mathrm{O}_{2}(\sim 30 \%$ in layers 2 and 3). Knowing that excluding the contribution of the drifts would only reinforce the trends described above, we can now suggest the following overall interpretation to explain these variations in $\mathrm{Chl} a, b_{\mathrm{bp}}$, and $\mathrm{O}_{2}$ in these three density layers during the eddy entrapment of bioprofiler \#4. In layer 1, the chlorophyll inventory seems to result from the combination of local biological processes with weak horizontal resupply from warmer, fresher, and less oxygenated water (Fig. 12a and d). In the middle density layer (layer 2), where mixing is considered insignificant because of the tightly grouped $T-S$ properties, the chlorophyll decrease does not seem to be due to local transformation to non-fluorescent detritus since no corresponding increase in the $b_{\mathrm{bp}}$ signal was observed (Fig. 13e). This leaves loss by settling or respiration as possible explanations. Loss by settling is certainly possible on this time frame (rates of only a few metres per day are required), and the high $b_{\text {bp }}$ values found in the lower density layer (layer 3 ) around profiles 160-180 could reflect transfer from the overlying layer (layer 2). Biomass loss by respiration and remineralisation to dissolved inorganic carbon is almost certainly also occurring given the decreasing oxygen inventories of layers 2 and 3 . For both these layers the rate of chlorophyll loss is too small (by factors of 2-3, assuming a moderately high phytoplankton C / Chl $a$ ratio of 50) to explain all the oxygen decrease, implying that degradation of detritus (represented by the decreasing particulate backscattering signal) and dissolved organic matter probably also contributes (this remains true even if we use a very high phytoplankton C / Chl $a$ ratio of 100; Cloern et al., 1995). For layer 3, remineralisation of settling particles coming from above with a minor remineralisation of local chlorophyll may best explain the slower decrease in chlorophyll in comparison to that of oxygen.

In combination, these results suggest that not all of the accumulated biomass was respired in the surface layer, with the
$\mathrm{CO}_{2}$ then returned to the atmosphere, and thus that there was some export. Quantifying this export amount is difficult and merits a modelling and sensitivity assessment that is beyond the scope of this paper. Here we simply provide an indication of its possible magnitude by comparison of the rates of mean oxygen loss in layer 1 (representing carbon likely to be returned to the atmosphere) vs. the subsurface layers 2 and 3 (representing carbon which may be exported in the ocean interior). The linear fits to the oxygen decreases for layers 1,2 , and 3 (as shown in Fig. 13) imply oxygen consumption rates of approximately 5,4 , and $4 \mu \mathrm{mol} \mathrm{m}{ }^{-3} \mathrm{~d}^{-1}$, respectively. These values lie towards the lower end of estimates for annual rates at mesopelagic depths (Sarmiento et al., 1990). Comparing $\mathrm{O}_{2}$ consumption of layers 2 and 3 (by multiplying the $\mathrm{O}_{2}$ consumption rate by the thickness and the average density of the layer) relative to the total mean consumption among the three layers, we estimate that $35 \%$ of the $\mathrm{CO}_{2}$ produced during this autumn period of bloom decline was exported from the surface layer (with $20 \%$ respired within layer 2 and $15 \%$ within layer 3 ). An analogous area of low to moderate production and relatively high export was observed during the KEOPS 2 field cruise just south of the Polar Front, in a meander area around $72.5^{\circ} \mathrm{E}-49^{\circ} \mathrm{S}$, where the flow considered as Lagrangian - was sampled at a few stations as a time series (Laurenceau-Cornec et al., 2015; Planchon et al., 2014). This area coincides with the location of the anticyclonic trajectory of bio-profiler \#3, around profile \#110, where moderate biomass production was observed (Fig. 5c), although spatial variations in this region unfortunately precluded estimation of biologically driven oxygen consumption from the bio-profiler.

\section{Conclusions}

The bio-profilers revealed several interesting aspects of the enriched biomass plume downstream from the Kerguelen Plateau by providing observations of its vertical dimension. First of all, the observations show that surface and total water column chlorophyll inventories are generally well correlated, which suggests that satellite perspectives on bloom spatial dynamics (e.g. Mongin et al., 2008, 2009) are unlikely to be strongly biased. This result holds true despite the presence of moderate ( $60 \%$ above surface values) subsurface chlorophyll maxima in up to $\sim 20 \%$ of all the profiles, and strong ( $100 \%$ above surface values) in $\sim 10 \%$ of all the profiles (Table 3 and Fig. 7). Furthermore, satellite surface observations seem to well reflect the water column relative range of mesoscale variability in biomass accumulations. However, the retrieval of water column Chl $a$ inventory from satellite surface observations is not simple. The bio-profilers often recorded significant quantities of biomass below the diel mixed layer, potentially correlated to the degree of shallowing of the mixed layer from deep winter values. The mixed layer at the time of the observations may not be the best parameter to quan- 
tify the chlorophyll inventories, especially when stratification by advection of lighter water mass or by seasonal warming creates strong density variations in the upper layer, and thus shallow mixed layers, and considering that chlorophyll production may have occurred much earlier than at the time of the observations. Of course, our work does not imply that satellite chlorophyll estimates are necessarily accurate. That is an issue which our data cannot address owing to the imprecision of the bio-optical sensors and the absence of calibration against local chlorophyll observations, an approach which recent work has shown to be necessary for satellite estimates as well (Johnson et al., 2013).

The occurrence of moderate subsurface chlorophyll maxima in our data (17\%) was higher than for results obtained with fluorescence sensors deployed on elephant seals around the Kerguelen Plateau ( 9\% using a criterion of $30 \%$ excess over surface values to define the maxima; Guinet et al., 2013). This may reflect the greater proportion of observations in the southern portion of the plume in the Guinet et al. (2013) study, a region where we also found that subsurface maxima were less common $(\sim 4 \%$ of profiles for bioprofiler \#2 for our moderate criterion of $60 \%$ excess, Table 3 , and $\sim 6 \%$ using their $30 \%$ criterion, data not shown). Subsurface maxima were also uncommon well downstream to the east of the Kerguelen Plateau. This is interesting in that it suggests that subsurface iron levels supplied by upwelling or vertical mixing were insufficient to drive biomass accumulations at the base of the mixed layer, or at least were less important than horizontal supply of Fe in surface waters. This is in contrast to Polar Frontal Zone waters much further to the east south of Australia, where persistent subsurface maxima have been observed (Parslow et al., 2001), and with observations from other autonomous profiling floats elsewhere in the Southern Ocean in which small subsurface maxima were found to be common in summer below the mixed layer (Carranza et al., 2015). Variations in the relative intensities of surface and deep iron supplies are a possible cause of these variations, but other processes may also be involved. As an example, the origin of the relatively more common and stronger subsurface chlorophyll maxima near the Gallieni Spur is not clear. Settling of surface biomass generated earlier in the season (Fig. 1) and/or seasonal depletion of iron in surface waters which reduces phytoplankton growth rates are possibilities, but they cannot be assessed given our lack of early seasonal observations. A third possibility of the overlaying of low-density waters southward across the Polar Front appears less likely, given that shipboard observations during KEOPS2 found that this process generated shallow high-biomass layers (at the Polar Frontal stations F-L, TEW7, and TEW-8; Lasbleiz et al., 2014; Trull et al., 2015).

Our initial research goals included looking for oxygen supersaturations in deep chlorophyll maxima to estimate net community production (Spitzer and Jenkins, 1989), but this could not be achieved owing to confounding effects on supersaturations from strong mixing with higher productivity overlying waters, and on aliasing of daily cycles by internal waves (Park et al., 2008a). Thus our results cannot address the issues of whether productivity in subsurface layers may partly explain offsets between satellite and in situ estimates of the Southern Ocean biological pump (Schlitzer, 2002) or whether the phytoplankton that grow in deep chlorophyll maxima are preferential contributors to carbon export (Kemp et al., 2000; Queguiner, 2013). We were able to make a first simple assessment of subsurface autumn oxygen consumption during the portion of the bio-profiler \#4 trajectory that delivered a quasi-Lagrangian time series, and this provided the very useful result that approximately $35 \%$ of the biomass respiration in that period occurred beneath the mixed layer, and thus at depths favouring $\mathrm{CO}_{2}$ export toward the ocean interior. This $35 \%$ can be approximately equated to an export / production " $e$ ratio" of 0.4 , which is relatively high by global standards, but in the middle of the large range of values observed in cold Southern Ocean waters (Maiti et al., 2013) and similar to $f$ ratios estimated for high-biomass waters over the central Kerguelen Plateau in autumn during the KEOPS1 campaign (Trull et al., 2008). Of course the subsequent fate of the exported $\mathrm{CO}_{2}$ inferred from the bio-profiler \#4 observations is uncertain, in that these waters were still within the depth range of possible exposure to the atmosphere during later deeper winter mixing, although the larger scale circulation in this region suggests it is a region dominated by subduction (Sallée et al., 2010).

Our simple correlative evaluation of the bio-profiler observations of biomass variations revealed that the highest chlorophyll levels were observed in surface waters with a narrow range of densities and moderate temperatures $(\sigma \sim$ $26.82 \pm 0.05 \mathrm{~kg} \mathrm{~m}^{-3}, T \sim 4 \pm 0.5^{\circ} \mathrm{C}$; Fig. 10). This occurrence of maximum biomass at moderate temperatures, along with the lack of correlation with mixed layer depth (Fig. 10), suggests that local controls on growth rates were less important than the history of the levels of iron supplied in this water type. Notably, water with these properties was found preferentially near the northern Kerguelen Plateau and Gallieni Spur, suggesting iron supply from this region. This is consistent with geostrophic circulation estimates and a favourable wind regime for upwelling in this region during the 2011 KEOPS2 period, when bio-profiler \#1 was deployed (d'Ovidio et al., 2015; Gille et al., 2014), and with Lagrangian analyses that backtrack water parcels to identify their origin. Further observations and analyses are of course necessary to determine the generality of this inference that the northern Kerguelen Plateau provides the major source of iron to the downstream biomass plume. This is especially true given the limited seasonal and interannual scope of our bio-profiler observations.

\section{The Supplement related to this article is available online at doi:10.5194/bg-12-2707-2015-supplement.}


Acknowledgements. This work was supported by the Australian Commonwealth Cooperative Research Program via the ACE CRC. M. Grenier was supported by a conjoint LEGOS and ACE CRC postdoctoral appointment and a CAMPUS FRANCE grant (FASIC award \#30418QG; campusfrance.org). A. Della Penna was supported by a conjoint Frontières du Vivant (Paris 7) and CSIRO-UTAS Quantitative Marine Science PhD scholarship. We thank Ann Thresher (CSIRO) for the harvesting and processing of the data from the bio-profilers, as supported by the Australian Integrated Marine Observing Argo and Southern Ocean Time Series facilities. We thank Cedric Cotté and Francesco d'Ovidio (LOCEAN, Universite de Paris VI) and the crew of the RV Marion Dufresne for bio-profiler deployments, and Stephane Blain and Bernard Quéguiner for KEOPS2 voyage leadership. Thanks to Vito Dirita, Alan Poole, and Craig Hanstein (CSIRO) for bio-profiler preparation, and Craig Neill and Kelly Brown (CSIRO) for oxygen optode calibrations. Thanks to Helen Phillips (IMAS) for fruitful discussions and advice concerning physical analyses of the hydrological variables, and Francesco d'Ovidio (LOCEAN, CNRS) for insights into Lagrangian perspectives on water parcel trajectories and their evolution. T. W. Trull and M. Grenier thank Catherine Jeandel for initiating this LEGOS-ACE CRC collaboration and hosting them to write the first draft. Finally, we gratefully acknowledge S. Thomalla and an anonymous reviewer for their valuable comments on an earlier version of the paper that allowed us to improve it significantly.

Edited by: S. Blain

\section{References}

Assmy, P., Smetacek, V., Montresor, M., Klaas, C., Henjes, J., Strass, V. H., Arrieta, J. M., Bathmann, U., Berg, G. M., and Breitbarth, E.: Thick-shelled, grazer-protected diatoms decouple ocean carbon and silicon cycles in the iron-limited Antarctic Circumpolar Current, P. Natl. Acad. Sci. USA, 110, 20633-20638, 2013.

Babin, M., Morel, A., and Gentili, B.: Remote sensing of sea surface sun-induced chlorophyll fluorescence: consequences of natural variations in the optical characteristics of phytoplankton and the quantum yield of chlorophyll a fluorescence, Int. J. Remote. Sens., 17, 2417-2448, 1996.

Behrenfeld, M. J.: Abandoning Sverdrup's Critical Depth Hypothesis on phytoplankton blooms, Ecology, 91, 977-989, 2010.

Biermann, L., Guinet, C., Bester, M., Brierley, A., and Boehme, L.: An alternative method for correcting fluorescence quenching, Ocean Sci., 11, 83-91, doi:10.5194/os-11-83-2015, 2015.

Blain, S., Queguiner, B., Armand, L., Belviso, S., Bombled, B., Bopp, L., Bowie, A., Brunet, C., Brussaard, C., Carlotti, F., Christaki, U., Corbiere, A., Durand, I., Ebersbach, F., Fuda, J.L., Garcia, N., Gerringa, L., Griffiths, B., Guigue, C., Guillerm, C., Jacquet, S., Jeandel, C., Laan, P., Lefevre, D., Lo Monaco, C., Malits, A., Mosseri, J., Obernosterer, I., Park, Y.-H., Picheral, M., Pondaven, P., Remenyi, T., Sandroni, V., Sarthou, G., Savoye, N., Scouarnec, L., Souhaut, M., Thuiller, D., Timmermans, K., Trull, T., Uitz, J., van Beek, P., Veldhuis, M., Vincent, D., Viollier, E., Vong, L., and Wagener, T.: Effect of natural iron fertilization on carbon sequestration in the Southern Ocean, Nature, 446, 10701071, doi:10.1038/nature05700, 2007.

Blain, S., Queguiner, B., and Trull, T.: The natural iron fertilization experiment KEOPS (KErguelen Ocean and Plateau compared Study): An overview, Deep-Sea Res. Pt II, 55, 559-565, doi:10.1016/j.dsr2.2008.01.002, 2008.

Blain, S., Renaut, S., Xing, X., Claustre, H., and Guinet, C.: Instrumented elephant seals reveal the seasonality in chlorophyll and light-mixing regime in the iron-fertilized Southern Ocean, Geophys. Res. Lett., 40, 6368-6372, doi:10.1002/2013GL058065, 2013.

Blain, S., Capparos, J., Guéneuguès, A., Obernosterer, I., and Oriol, L.: Distributions and stoichiometry of dissolved nitrogen and phosphorus in the iron-fertilized region near Kerguelen (Southern Ocean), Biogeosciences, 12, 623-635, doi:10.5194/bg-12623-2015, 2015.

Boss, E. and Pegau, W. S.: Relationship of light scattering at an angle in the backward direction to the backscattering coefficient, Appl. Optics, 40, 5503-5507, 2001.

Boyd, P. W. and Ellwood, M. J.: The biogeochemical cycle of iron in the ocean, Nat. Geosci., 3, 675-682, doi:10.1038/ngeo964, 2010.

Boyd, P. W. and Trull, T. W.: Understanding the export of marine biogenic particles: is there consensus?, Prog. Oceanogr., 4, 276312, doi:210.1016/j.pocean.2006.1010.1007, 2007.

Boyd, P., LaRoche, J., Gall, M., Frew, R., and McKay, R. L. M.: Role of iron, light, and silicate in controlling algal biomass in subantarctic waters SE of New Zealand, J. Geophys. Res., 104, 13395-13408, 1999.

Boyd, P. W., Crossley, A. C., DiTullio, G. R., Griffiths, F. B., Hutchins, D. A., Queguiner, B., Sedwick, P. N., and Trull, T. W.: Control of phytoplankton growth by iron supply and irradiance in the subantarctic Southern Ocean: Experimental results from the SAZ Project, J. Geophys. Res., 106, 31573-31584, 2001.

Boyd, P. W., Jickells, T., Law, C. S., Blain, S., Boyle, E. A., Buesseler, K. O., Coale, K. H., Cullen, J. J., de Baar, H. J. W., Follows, M., Harvey, M., Lancelot, C., Levasseur, M., Owens, N. P. J., Pollard, R., Rivkin, R. B., Sarmiento, J., Schoemann, V., Smetacek, V., Takeda, S., Tsuda, A., Turner, S., and Watson, A. J.: Mesoscale Iron Enrichment Experiments 19932005: Synthesis and Future Directions, Science, 315, 612-617, doi:10.1126/science.1131669, 2007.

Carranza, M. M., Gille, S. T., Franks, P. J. S., Girton, J. B., and Johnson, K. S.: Mixed-layer depth and Chl $a$ variability in the Southern Ocean, ICES J. Mar. Sci., submitted, 2015.

Cavagna, A. J., Fripiat, F., Elskens, M., Dehairs, F., Mangion, P., Chirurgien, L., Closset, I., Lasbleiz, M., Flores-Leiva, L., Cardinal, D., Leblanc, K., Fernandez, C., Lefèvre, D., Oriol, L., Blain, S., and Quéguiner, B.: Biological productivity regime and associated $\mathrm{N}$ cycling in the vicinity of Kerguelen Island area, Southern Ocean, Biogeosciences Discuss., 11, 18073-18104, doi:10.5194/bgd-11-18073-2014, 2014.

Cetinić, I., Perry, M. J., Briggs, N. T., Kallin, E., D’Asaro, E. A., and Lee, C. M.: Particulate organic carbon and inherent optical properties during 2008 North Atlantic Bloom Experiment, J. Geophys. Res., 117, C06028, doi:10.1029/2011JC007771, 2012.

Cloern, J. E., Grenz, C., and Vidergar-Lucas, L.: An empirical model of the phytoplankton chlorophyll: carbon ratio-the conservation factor between productivity and growth rate, Limnol. Oceanogr., 40, 1313-1321, 1995. 
Constable, A. J., Nicol, S., and Strutton, P. G.: Southern Ocean productivity in relation to spatial and temporal variation in the physical environment, J. Geophys. Res.-Oceans, 108, 8079, doi:8010.1029/2001JC001270, 2003.

Cullen, J. J.: The deep chlorophyll maximum: comparing vertical profiles of chlorophyll $a$, Can. J. Fish. Aquat. Sci., 39, 791-803, 1982.

de Baar, H. J. W., de Jong, J. T. M., Bakker, D. C. E., Loscher, B. M., Veth, C., Bathmann, U., and Smetacek, V.: Importance of iron for phytoplankton blooms and carbon dioxide drawdown in the Southern Ocean, Nature, 373, 412-415, 1995.

d'Ovidio, F., De Monte, S., Della Penna, A., Cotté, C., and Guinet, C.: Ecological implications of eddy retention in the open ocean: a Lagrangian approach, J. Phys. A-Math Theor., 46, 254023, doi:10.1088/1751-8113/46/25/254023, 2013.

d'Ovidio, F., Della Penna, A., Trull, T. W., Nencioli, F., Pujol, I., Rio, M. H., Park, Y.-H., Cotté, C., Zhou, M., and Blain, S.: The biogeochemical structuring role of horizontal stirring: Lagrangian perspectives on iron delivery downstream of the Kerguelen plateau, Biogeosciences Discuss., 12, 779-814, doi:10.5194/bgd-12-779-2015, 2015.

Earp, A., Hanson, C. E., Ralph, P. J., Brando, V. E., Allen, S., Baird, M., Clementson, L., Daniel, P., Dekker, A. G., and Fearns, P. R.: Review of fluorescent standards for calibration of in situ fluorometers: Recommendations applied in coastal and ocean observing programs, Opt. Express, 19, 26768-26782, 2011.

Falkowski, P. G. and Kiefer, D. A.: Chlorophyll a fluorescence in phytoplankton: relationship to photosynthesis and biomass, J. Plankton Res., 7, 715-731, 1985.

Falkowski, P. G. and Kolber, Z.: Variations in chlorophyll fluorescence yields in phytoplankton in the world oceans, Aust. J. Plant Physiol., 22, 341-355, 1995.

Fennel, K. and Boss, E.: Subsurface maxima of phytoplankton and chlorophyll: Steady ${ }^{\circledR}$ solutions from a simple model, Limnol. Oceanogr., 48, 1521-1534, 2003.

Gille, S. T., Carranza, M. M., Cambra, R., and Morrow, R.: Windinduced upwelling in the Kerguelen Plateau region, Biogeosciences, 11, 6389-6400, doi:10.5194/bg-11-6389-2014, 2014.

Goericke, R. and Montoya, J. P.: Estimating the contribution of microalgal taxa to chlorophyll a in the field-variations of pigment ratios under nutrient-and light-limited growth, Mar. Ecol.-Prog. Ser., 169, 97-112, 1998.

Gordon, H. R. and McCluney, W. R.: Estimation of the depth of Sun light penetration in the sea for remote sensing, Appl. Opt., 14, 413-416, 1975.

Guinet, C., Xing, X., Walker, E., Monestiez, P., Marchand, S., Picard, B., Jaud, T., Authier, M., Cotté, C., Dragon, A. C., Diamond, E., Antoine, D., Lovell, P., Blain, S., D’Ortenzio, F., and Claustre, H.: Calibration procedures and first data set of Southern Ocean chlorophyll $a$ profiles collected by elephant seal equipped with a newly developed CTD-fluorescence tags, Earth Syst. Sci. Data, 5, 15-29, doi:10.5194/essd-5-15-2013, 2013.

Huot, Y., Babin, M., Bruyant, F., Grob, C., Twardowski, M. S., and Claustre, H.: Relationship between photosynthetic parameters and different proxies of phytoplankton biomass in the subtropical ocean, Biogeosciences, 4, 853-868, doi:10.5194/bg-4853-2007, 2007.
Johnson, R., Strutton, P. G., Wright, S. W., McMinn, A., and Meiners, K. M.: Three improved satellite chlorophyll algorithms for the Southern Ocean, J. Geophys. Res.-Oceans, 118, 1-10, 2013.

Jouandet, M.-P., Trull, T. W., Guidi, L., Picheral, M., Ebersbach, F., Stemmann, L., and Blain, S.: Optical imaging of mesopelagic particles indicates deep carbon flux beneath a natural ironfertilized bloom in the Southern Ocean, Limnol. Oceanogr., 56, 1130-1140, doi:10.4319/lo.2011.56.3.1130, 2011.

Joubert, W. R., Swart, S., Tagliabue, A., Thomalla, S. J., and Monteiro, P. M. S.: The sensitivity of primary productivity to intraseasonal mixed layer variability in the sub-Antarctic Zone of the Atlantic Ocean, Biogeosciences Discuss., 11, 4335-4358, doi:10.5194/bgd-11-4335-2014, 2014.

Kemp, A. E. S., Pike, J., Pearce, R. B., and Lange, C. B.: The "Fall dump" - a new perspective on the role of a "shade flora" in the annual cycle of diatom production and export flux, Deep-Sea Res. Pt II, 47, 2129-2154, 2000.

Kiefer, D. A.: Fluoresence properties of natural phytoplankton populations, Mar. Biol., 22, 263-269, 1973.

Lasbleiz, M., Leblanc, K., Blain, S., Ras, J., Cornet-Barthaux, V., Hélias Nunige, S., and Quéguiner, B.: Pigments, elemental composition $(\mathrm{C}, \mathrm{N}, \mathrm{P}$, and $\mathrm{Si}$ ), and stoichiometry of particulate matter in the naturally iron fertilized region of Kerguelen in the Southern Ocean, Biogeosciences, 11, 5931-5955, doi:10.5194/bg-115931-2014, 2014.

Laurenceau-Cornec, E. C., Trull, T. W., Davies, D. M., Bray, S. G., Doran, J., Planchon, F., Carlotti, F., Jouandet, M.-P., Cavagna, A.-J., Waite, A. M., and Blain, S.: The relative importance of phytoplankton aggregates and zooplankton fecal pellets to carbon export: insights from free-drifting sediment trap deployments in naturally iron-fertilised waters near the Kerguelen Plateau, Biogeosciences, 12, 1007-1027, doi:10.5194/bg-121007-2015, 2015.

Lenton, A., Tilbrook, B., Law, R. M., Bakker, D., Doney, S. C., Gruber, N., Ishii, M., Hoppema, M., Lovenduski, N. S., Matear, R. J., McNeil, B. I., Metzl, N., Mikaloff Fletcher, S. E., Monteiro, P. M. S., Rödenbeck, C., Sweeney, C., and Takahashi, T.: Seaair $\mathrm{CO}_{2}$ fluxes in the Southern Ocean for the period 1990-2009, Biogeosciences, 10, 4037-4054, doi:10.5194/bg-10-4037-2013, 2013.

Le Quéré, C., Takahashi, T., Buitenhuis, E. T., Rödenbeck, C., and Sutherland, S. C.: Impact of climate change and variability on the global oceanic sink of $\mathrm{CO}_{2}$, Global Biogeochem. Cy., 24, GB4007, doi:10.1029/2009GB003599, 2010.

Levitus, S.: Climatological atlas of the world ocean, NOAA Prof. Pap. 13, 173 pp., US Govt. Printing Off., Washington, USA, 1982.

Levy, M.: Mesoscale variability of phytoplankton and of new production: Impact of the large-scale nutrient distribution, J. Geophys. Res., 108, 3358, doi:3310.1029/2002JC001577, 2003.

Maiti, K., Charette, M. A., Buesseler, K. O., and Kahru, M.: An inverse relationship between production and export efficiency in the Southern Ocean, Geophys. Res. Lett., 40, 1557-1561, 2013.

Martin, J. H.: Glacial-interglacial $\mathrm{CO}_{2}$ change: The iron hypothesis, Paleoceanography, 5, 1-13, 1990.

Martinez, E., Antoine, D., D’Ortenzio, F., and Gentili, B.: Climatedriven basin-scale decadal oscillations of oceanic phytoplankton, Science, 326, 1253-1256, 2009. 
Matear, R., Hirst, A. C., and McNeil, B. I.: Changes in dissolved oxygen in the Southern Ocean with climate change, Geochem. Geophy. Geosy., 1, 1050, doi:10.1029/2000GC000086, 2000.

Mongin, M., Molina, E., and Trull, T. W.: Seasonality and scale of the Kerguelen plateau phytoplankton bloom: A remote sensing and modeling analysis of the influence of natural iron fertilization in the Southern Ocean, Deep-Sea Res. Pt II, 55, 880-892, doi:10.1016/j.dsr2.2007.12.039, 2008.

Mongin, M., Abraham, E. R., and Trull, T. W.: Winter advection of iron can explain the summer phytoplankton bloom that extends $1000 \mathrm{~km}$ downstream of the Kerguelen Plateau in the Southern Ocean, J. Mar. Res., 67, 225-237, 2009.

Moore, J. K. and Abbott, M. R.: Phytoplankton chlorophyll distributions and primary production in the Southern Ocean, J. Geophys. Res., 105, 28,709-28,722, 2000.

Morel, A. and Maritorena, S.: Bio-optical properties of oceanic waters: A reappraisal, J. Geophys. Res., 106, 7163-7180, 2001.

Mosseri, J., Queguiner, B., Armand, L.K., and Cornet-Barthaux, V.: Impact of iron on silicon utilization by diatoms in the Southern Ocean: A case study of Si/N cycle decoupling in a naturally ironenriched area, Deep-Sea Res. Pt II, 55, 801-819, 2008.

Nicol, S., Pauly, T., Vindoff, N., Wright, S., Thiele, D., Hosie, G., Strutton, P., and Woehler, E.: Ocean circulation off East Antarctica affects ecosystem structure and sea-ice extent, Nature, 406, 504-507, 2000

Nielsdóttir, M. C., Bibby, T. S., Moore, C. M., Hinz, D. J., Sanders, R., Whitehouse, M. J., Korb, R. E., and Achterberg, E. P.: Seasonal and spatial dynamics of iron availability in the Scotia Sea, Mar. Chem., 130-131, 62-72, 2012.

Oka, E. and Ando, K.: Stability of temperature and conductivity sensors of Argo profiling floats, J. Oceanogr., 60, 253-258, 2004.

Orsi, A. H., Whitworth, T. I., and Nowlin, W. D. J.: On the meridional extent and fronts of the Antarctic Circumpolar Current, Deep-Sea Res. Pt I, 42, 641-673, 1995.

Park, Y.-H., Charriaud, E., Ruiz Pino, D., and Jeandel, C.: Seasonal and interannual variability of the mixed layer properties and steric height at station KERFIX, southwest of Kerguelen, J. Marine Syst., 17, 571-586, 1998.

Park, Y.-H., Fuda, J.-L., Durand, I., and Naveira Garabato, A. C.: Internal tides and vertical mixing over the Kerguelen Plateau, Deep-Sea Res. Pt II, 55, 582-593, 2008a.

Park, Y.-H., Roquet, F., Fuda, J.-L., and Durand, I.: Large scale circulation over and around the Kerguelen Plateau, Deep-Sea Res. Pt II, 55, 566-581, 2008b.

Park, Y.-H., Durand, I., Kestenare, E., Rougier, G., Zhou, M., d'Ovidio, F., Cotté, C., and Lee, J.-H.: Polar Front around the Kerguelen Islands: An up-to-date determination and associated circulation of surface/subsurface waters, J. Geophys. Res.Oceans, 119, 6575-6592, doi:10.1002/2014JC010061, 2014a.

Park, Y.-H., Lee, J.-H., Durand, I., and Hong, C.-S.: Validation of Thorpe-scale-derived vertical diffusivities against microstructure measurements in the Kerguelen region, Biogeosciences, 11, 6927-6937, doi:10.5194/bg-11-6927-2014, 2014b.

Parslow, J., Boyd, P., Rintoul, S. R., and Griffiths, F. B.: A persistent sub-surface chlorophyll maximum in the Polar Frontal Zone south of Australia: seasonal progression and implications for phytoplankton-light-nutrient interactions, J. Geophys. Res., 106, 31543-31557, 2001.
Planchon, F., Ballas, D., Cavagna, A.-J., Bowie, A. R., Davies, D., Trull, T., Laurenceau, E., Van Der Merwe, P., and Dehairs, F.: Carbon export in the naturally iron-fertilized Kerguelen area of the Southern Ocean based on the ${ }^{234} \mathrm{Th}$ approach, Biogeosciences Discuss., 11, 15991-16032, doi:10.5194/bgd11-15991-2014, 2014.

Pollard, R. T., I.Salter, Sanders, R. J., Lucas, M. I., Moore, C. M., Mills, R. A., Statham, P. J., Allen, J. T., Baker, A. R., Bakker, D. C. E., Charette, M. A., Fielding, S., Fones, G. R., French, M., Hickman, A. E., Holland, R. J., Hughes, J. A., Jickells, T. D., Lampitt, R. S., Morris, P. J., Nédélec, F. H., Nielsdóttir, M., Planquette, H., Popova, E. E., Poulton, A. J., Read, J. F., Seeyave, S., Smith, T., Stinchcombe, M., Taylor, S., Thomalla, S., Venables, H. J., Williamson, R., and Zubkov, M. V.: Southern Ocean deep-water carbon export enhanced by natural iron fertilization, Nature, 457, 577-580, doi:510.1038/nature07716, 2009.

Queguiner, B.: Iron fertilization and the structure of planktonic communities in high nutrient regions of the Southern Ocean, Deep-Sea Res. Pt II, 90, 43-54, 2013.

Sackmann, B. S., Perry, M. J., and Eriksen, C. C.: Seaglider observations of variability in daytime fluorescence quenching of chlorophyll-a in Northeastern Pacific coastal waters, Biogeosciences Discuss., 5, 2839-2865, doi:10.5194/bgd-5-2839-2008, 2008.

Sallée, J.-B., Speer, K., Rintoul, S., and Wijffels, S.: Southern Ocean thermocline ventilation, J. Phys. Oceangr., 40, 509-529, 2010.

Salter, I., Lampitt, R. S., Sanders, R., Poulton, A., Kemp, A. E. S., Boorman, B., Saw, K., and Pearce, R.: Estimating carbon, silica and diatom export from a naturally fertilised phytoplankton bloom in the Southern Ocean using PELAGRA: A novel drifting sediment trap, Deep-Sea Res. Pt II, 54, 2233-2259, 2007.

Sanial, V., van Beek, P., Lansard, B., d'Ovidio, F., Kestenare, E., Souhaut, M., Zhou, M., and Blain, S.: Study of the phytoplankton plume dynamics off the Crozet Islands (Southern Ocean): A geochemical-physical coupled approach, J. Geophys. Res.Oceans, 119, 2227-2237, 2014.

Sarmiento, J. L. and Le Quéré, C.: Oceanic carbon dioxide uptake in a model of century-scale global warming, Science, 274, 13461350, 1996.

Sarmiento, J. L., Thiele, G., Key, R. M., and Moore, W. S.: Oxygen and nitrate new production and remineralization i the North Atlantic subtropical gyre, J. Geophys. Res.-Oceans, 95, 18303$18315,1990$.

Sarmiento, J. L., Gruber, N., Brzezinski, M. A., and Dunne, J. P.: High-latitude controls of thermocline nutrients and low latitude biological productivity, Nature, 427, 56-60, 2004.

Savoye, N., Dehairs, F., Elskens, M., Cardinal, D., Kopczynska, E. E., Trull, T. W., Wright, S., Baeyens, W., and Griffiths, F. B.: Regional variation of spring N-uptake and new production in the Southern Ocean, Geophys. Res. Lett., 31, L03301, doi:03310.01029/02003GL018946, 2004.

Savoye, N., Trull, T. W., Jacquet, S. H. M., Navez, J., and Dehairs, F.: 234Th-based export fluxes during a natural iron fertilization experiment in the Southern Ocean (KEOPS), Deep-Sea Res. Pt II, 55, 841-855, 2008.

Schlitzer, R.: Carbon export fluxes in the Southern Ocean: results from inverse modeling and comparison with satellite-based estimates, Deep-Sea Res. Pt II, 49, 1623-1644, 2002. 
Shadwick, E. H., Tilbrook, B., Cassar, N., Trull, T. W., and Rintoul, S. R.: Summertime physical and biological controls on $\mathrm{O}_{2}$ and $\mathrm{CO}_{2}$ in the Australian Sector of the Southern Ocean, J. Mar. Syst., in press, doi:10.1016/j.jmarsys.2013.12.008, 2014.

Shadwick, E. H., Trull, T. W., Tilbrook, B., Sutton, A., Schulz, E., and Sabine, C. L.: Seasonality of biological and physical controls on surface ocean $\mathrm{CO}_{2}$ from hourly observations at the Southern Ocean Time Series site south of Australia, Global Biogeochem. Cy., 29, 223-238, doi:10.1002/2014GB004906, 2015.

Sigman, D. M. and Boyle, E. A.: Glacial/Interglacial variations in atmospheric carbon dioxide, Nature, 407, 859-869, 2000.

Sokolov, S. and Rintoul, S. R.: On the relationship between fronts of the Antarctic Circumpolar Current and surface chlorophyll concentrations in the Southern Ocean, J. Geophys. Res.-Oceans, 112, C07030, doi:10.1029/2006JC004072, 2007.

Sokolov, S. and Rintoul, S. R.: Circumpolar structure and distribution of the Antarctic Circumpolar Current fronts: 1. Mean circumpolar paths, J. Geophys. Res., 114, C11018, doi:10.1029/2008JC005108, 2009.

Spitzer, W. S. and Jenkins, W. J.: Rates of vertical mixing, gas exchange and new production: Estimates from seasonal gas cycles in the upper ocean near Bermuda, J. Mar. Res., 47, 169-196, 1989.

Stramski, D., Reynolds, R. A., Babin, M., Kaczmarek, S., Lewis, M. R., Röttgers, R., Sciandra, A., Stramska, M., Twardowski, M. S., Franz, B. A., and Claustre, H.: Relationships between the surface concentration of particulate organic carbon and optical properties in the eastern South Pacific and eastern Atlantic Oceans, Biogeosciences, 5, 171-201, doi:10.5194/bg-5-171-2008, 2008.

Suggett, D. J., Prášil, O., and Borowitzka, M. A.: Chlorophyll $a$ fluorescence in aquatic sciences: methods and applications, Developments in Applied Phycology, Springer, Dordrecht, 323 pp., doi:10.1007/978-90-481-9268-7, 2011.

Sullivan, J. M., Twardowski, M. S., Zaneveld, R. J. V., and Moore, C. C.: Measuring optical backscattering in water, in: Light Scattering Reviews 7: Radiative Transfer and Optical Properties of Atmosphere and Underlying Surface, edited by: Kokhanovsky, A., Chichester UK, Springer Praxis Books, 189-224, 2013.

Sverdrup, H. U.: On the conditions for the vernal blooming of phytoplankton, J. Conseil, 18, 287-295, 1953.

Swart, S., Thomalla, S., and Monteiro, P.: The seasonal cycle of mixed layer dynamics and phytoplankton biomass in the SubAntarctic Zone: A high-resolution glider experiment, J. Marine Syst., 2014.
Taylor, J. R. and Ferrari, R.: Shutdown of turbulent convection as a new criterion for the onset of spring phytoplankton blooms, Limnol. Oceanogr., 56, 2293-2307, 2011.

Thomalla, S. J., Fauchereau, N., Swart, S., and Monteiro, P. M. S.: Regional scale characteristics of the seasonal cycle of chlorophyll in the Southern Ocean, Biogeosciences, 8, 2849-2866, doi:10.5194/bg-8-2849-2011, 2011.

Trull, T. W., Bray, S. G., Manganini, S. J., Honjo, S., and François, R.: Moored sediment trap measurements of carbon export in the Subantarctic and Polar Frontal Zones of the Southern Ocean, south of Australia, J. Geophys. Res., 106, 31489-31510, 2001.

Trull, T. W., Davies, D., and Casciotti, K.: Insights into nutrient assimilation and export in naturally iron-fertilized waters of the Southern Ocean from nitrogen, carbon and oxygen isotopes, Deep-Sea Res. Pt II, 55, 820-840, doi:10.1016/j.dsr2.2007.12.035, 2008.

Trull, T. W., Davies, D. M., Dehairs, F., Cavagna, A.-J., Lasbleiz, M., Laurenceau-Cornec, E. C., d'Ovidio, F., Planchon, F., Leblanc, K., Quéguiner, B., and Blain, S.: Chemometric perspectives on plankton community responses to natural iron fertilisation over and downstream of the Kerguelen Plateau in the Southern Ocean, Biogeosciences, 12, 1029-1056, doi:10.5194/bg-121029-2015, 2015.

Watson, A. J., Bakker, D. C. E., Ridgwell, A. J., Boyd, P. W., and Law, C. S.: Effect of iron supply on Southern Ocean $\mathrm{CO}_{2}$ uptake and implications for glacial for atmospheric $\mathrm{CO}_{2}$, Nature, 407, 730-733, 2000.

Weeding, B. and Trull, T. W.: Hourly oxygen and total gas tension measurements at the Southern Ocean Time Series site reveal winter ventilation and spring net community production, J. Geophys Res.-Oceans, 119, 348-358, doi:10.1002/2013JC009302, 2014.

Xing, X., Claustre, H., Blain, S., d'Ortenzio, F., Antoine, D., Ras, J., and Guinet, C.: Quenching correction for in vivo chlorophyll fluorescence acquired by autonomous platforms: A case study with instrumented elephant seals in the Kerguelen region (Southern Ocean), Limnol. Oceanogr., 10, 483-495, 2012.

Zhang, X., Hu, L., and He, M.-X.: Scattering by pure seawater: effect of salinity, Opt. Express, 17, 5698-5710, 2009. 